\title{
Why do (or don't) people carpool for long distance trips? A discrete choice experiment in France
}

\author{
Guillaume Monchambert ${ }^{l}$
}

December 11, 2019

\begin{abstract}
Long-distance carpooling is an emerging mode in France and Europe, but little is known about monetary values of this mode attributes in transport economics. We conducted a discrete choice experiment to identify and measure the values of attributes of long-distance transport modes for a trip as a driver and as a passenger, with a special focus on carpooling. Around 1.700 French individuals have been surveyed. We use discrete mixed logit models to estimate the probability of mode choice. We find that the value of travel time for a driver who carpools is on average 13\% higher than the value of travel time when driving alone in his/her car. The average value of travel time for a carpool trip as passenger is around 26 euros per hour, $60 \%$ higher than for a train trip and 20\% higher than for a bus trip. Moreover, our study confirms a strong preference for driving solo over taking carpoolers in one's car. We also show that individuals traveling as carpool passenger incur a "discomfort" cost of on average 4.5 euros per extra passenger in the same vehicle. Finally, we identify robust socio-economic effects affecting the probability of carpooling, especially gender effects. When they drive a car, females are less likely to carpool than male, but they prefer to carpool two passengers over only one passenger.
\end{abstract}

JEL Codes: R41; C35

Keywords: Value of time; Long-distance; Carpooling; Discrete choice experiment

\footnotetext{
${ }^{1}$ Affiliation: University of Lyon - Transport, Urban Planning and Economics Laboratory, 14 avenue Berthelot, F69363 Lyon Cedex 07 France - g.monchambert@univ-lyon2.fr.

Funding: This research was supported by the "Programme Avenir Lyon Saint-Etienne de l'Université de Lyon" within the program "Investissements d'Avenir" (ANR-11-IDEX-0007).

Acknowledgments: We thank the editor and three referees for very useful comments and suggestions. We also thank Yves Croissant, Alix Le Goff and Charles Raux for their valuable comments, and participants at the Annual Conference of the International Economics Association (ITEA) in Honk Kong, June 2018.
} 


\section{Introduction}

Every month in France, more than one million people use the leading carpooling platform (Blablacar.com) to carpool for a long-distance trip. ${ }^{2}$ According to CGDD (2016), long-distance carpoolers travelled 6 billion kilometers in 2015, which is $2.72 \%$ of the long-distance kilometers made by travelers in France. This trend is not France-specific: BlaBlaCar has now expanded to 22 countries across Europe, Asia, and Latin America and the platform claims more than 40 million users at the beginning of 2017 (Barrat, 2017) and 65 million at the end of 2018 (White, 2018). The success met by carpooling after 2010 is related to two factors: the sharing economy and emergence of online platforms (Montero, 2019).

Public policy makers very often consider carpool as a cost-effective way to moderate road congestion and gas emissions. ${ }^{3}$ Indeed low car occupancy rates imply that there is an unused transport capacity. The use of these empty seats allows to decrease congestion at low cost if new carpool passengers are exdrivers. However, the carpool mode share is low in France, despite a price that is often three to four times cheaper than the train (Razemon, 2013). Some local authorities in France promote carpooling by implementing carpool parking and experimenting lane reserved to high occupancy vehicles (see for example the cities of Lyon and Grenoble). It is then crucial to understand who carpool, who do not, and why to improve the efficiency of such policies.

Around 14\% of passenger-km on road were made during long distance trips in France in 2016 (SDES, 2018). Long distance trips are a good opportunity to promote carpooling for two reasons. First, the matching process is simpler than for short-distance trips because the scheduling constraints are lower (ADEME, 2015b). Second, the long distance trips are concentrated in time (especially during week-ends

\footnotetext{
${ }^{2}$ The carpool trip distance average is around 360km (ADEME 2015a).

${ }^{3}$ This analysis is still debated. A recent study using BlaBlaCar's real usage data over 12 months and a survey on 6,884 BlaBlaCar users shows an overall positive impact of BlaBlaCar on $\mathrm{CO} 2$ emissions (BlaBlaCar \& Le BIPE, 2019). Wagner (2016) suggests that there is no evidence that the carpool development in France allows to decrease road traffic, because on the one hand most carpool passengers come from transit and not from private cars, and on the other hand, some carpool drivers ( $16 \%$ according to Wagner's study) would have not made the trip without monetary reward due to carpool. Using existing European data, Finger et al. (2017) reveal that the raise of carpooling is explained by a migration of substantial number of passengers from traditional long-distance public transport services. This is one of the reasons why Wang (2011) suggests to not award carpoolers with public resources such as free parking or high-occupancy lanes in China.
} 
and holidays) and space (mainly on highways), leading to severe road congestion. Carpooling development is a promising solution to this issue.

Therefore there is a need for new empirical evidence to better understand attitudes towards long-distance carpool and improve public policies. Despite the significant long-distance carpool raise, little is known about this successful but not new (see Teal, 1987) transport mode. Neoh et al. (2017) propose a metaanalysis of 22 studies evaluating factors of carpooling. They find that factors such as "number of employees", "partner matching programs", "female" and "fixed work schedule" have strong effects on carpooling decision (see also Charles \& Kline (2006), Buliung et al. (2010), Correia \& Viegas (2011), and De Luca \& Di Pace (2015) for studies on the determinants of short-distance carpooling).

However, most of these studies look at short distance trips, especially commute to work and characteristics of daily commuting trips differ from those of occasional long-distance trips (Dargay \& Clark, 2012). Few studies address long-distance carpooling specificities. Delhomme \& Gheorghiu (2016) study characteristics and motivational factors upon which carpoolers and non-carpoolers differ. They find that carpoolers are more likely to be women and have children. Carpoolers also have positive attitude towards public transport and tend to be more environmentally aware. Shaheen et al. (2017) use an online survey of $618 \mathrm{BlaBlaCar}$ members in France to show that carpoolers are on average younger than the French population, and respondents with high income level carpool more often as driver whereas lows income respondents are more often carpool passengers. Farajallah et al. (2019) observe how price and demand are determined on BlaBlaCar platform. Controlling for price, they observe that the fraction of seats sold is three percentage points higher for female drivers than for males. In an extensive qualitative survey carried out by the French Environment and Energy Management Agency (ADEME, 2015a), interviewed carpoolers state they carpool because this transport mode is, in order of importance, convivial, cheap, flexible, environmentally friendly and comfortable. These statements are to be tested through theoretical and empirical studies.

This paper focuses on the determinants of carpool choice for long-distance trips (100-700 km). As in Delhomme \& Gheorgiu (2016), we define carpool as an arrangement where two or more people, not 
belonging to the same household, share the use of privately owned ${ }^{4}$ car for a trip, and the passengers contribute to the driver's expenses. ${ }^{5}$ In this framework, we address the following research questions: what are the determinants of carpool choice for long-distance trips? We especially test the following hypothesis: (i) Carpool Value of Travel Time (VoTT) is lower than in other modes. If, as it is stated by respondent to the ADEME survey (2015a), conviviality is the main reason for long-distance carpooling, then we expect carpool travel time to be more enjoyable than in other modes, and the carpool VoTT to be lower than in other modes. (ii) An extra carpooling passenger in the car decreases the probability of choosing carpool. An extra passenger in the car mechanically decreases the space available for other individuals in the car, making the trip less convenient. (iii) Female are more likely to carpool than male. This hypothesis is motivated by findings for short-distance trips (Patterson et al., 2005, Buliung et al., 2009).

We respond to these questions by measuring carpool VoTT for a trip as a driver and as a passenger, comparing them with other modes VoTT, and by measuring the value of an extra passenger from a driver and a passenger perspective. We also observe and measure channels by which individuals' socioeconomic characteristics affect these elements. To this aim, a stated choices experiment survey was conducted in France.

To our knowledge, we are the first to empirically measure and valuate the attributes of long-distance carpooling, especially the VoTT and the effect of the number of passengers. This paper also contributes to the literature estimating mode-specific VoTT. We show that carpool VoTT is greater than competing modes VoTT, and that additional passenger in the vehicle is perceived as a cost by individuals, both as driver and as passenger. The econometric analysis also reveals strong and mode-dependent gender effects.

Results are of interest for several reasons. First, they bring information to improve carpool organization. We show that the effect of the number of individuals traveling together in a vehicle on the utility may

\footnotetext{
${ }^{4}$ Private property is an important carpooling feature because it distinguishes it from car-sharing, where the same vehicle is owned by several persons.

${ }^{5}$ Carpooling is known as ridesharing in North America.
} 
vary depending on individual characteristics. This means that carpool platforms may increase efficiency by adapting their supply to individual characteristics. Second, our estimations of carpool-specific VoTT are of interest to implement public policies aiming at increase vehicles occupation rate for long distance trips. They can be used to sharpen high-occupancy vehicles lane and tolls. Last but not least, most long distance travel models do no differentiate carpool and solo travel. Our study reveal significant differences between these two modes. Therefore one should implement some of our findings in travel demand forecasting models.

In this study, we do not investigate the choice between being a driver or a passenger. Indeed, this choice rests on a multitude of variables difficult to implement in a discrete choice experiment survey, such that the need for a car at destination. Consequently, we investigate separately the choice of mode for drivers on the one hand, and the choice of mode for passengers on the other hand.

The rest of the paper is organized as follows. Section 2 presents the survey design used to elicit preferences and summary statistics. Section 3 presents the theoretical framework and the empirical strategy used to measure VoTT and the effect of extra carpool passenger. Section 4 presents results. A general discussion is given in Section 5. Section 6 concludes.

\section{Survey design, sampling and data structure}

\subsection{The sample}

A stated choice experiment was used to collect data to examine the trade-off between travel time, price (or gain) of the trip and number of passengers in the car for trips both as driver and as passenger. An internet-based survey instrument was used. The data were collected in March and April 2017 involving respondents residing in France. The survey has been conducted by an Internet panel provider on a national sample. ${ }^{6}$ The sample is representative of the French population over 18 years old according to the quota method (gender, age, income and occupation).

\footnotetext{
${ }^{6}$ Individuals received an email with a hyperlink to the online survey. This email was neutral to avoid selection bias. We did not want individuals interested in mobility issues to be overrepresented in our sample. The Internet panel provider has its own algorithm to send the appropriate quantity of mails according to the characteristics of the individuals. This algorithm is dynamic to take into account the individuals who already took the survey. The
} 
We implement two distinct sub-experiments in this survey, one for trips as "driver" and the other for trips as "passenger". The reason is that many factors affecting the choice of making the trip as a driver or as a passenger cannot be implemented in a discrete choice experiment in a satisfactory way. This choice is likely to be correlated with many factors that can hardly be controlled in a discrete choice experiment. Examples of these factors are the need of having a car at destination, the length of the stay... Therefore we decided to secure the conditions of the experimentation and to impose the distinction between a trip as a driver and a trip as a passenger in an arbitrary way.

In the survey, one respondent participated to the driver sub-experiment or to the passenger subexperiment, but not both. The sub-experiments sampling has been made according to car ownership and driving license criteria. Individuals without car or without driving license were not considered as potential drivers, so they went to the passenger sub-experiment. Among individuals with a car and a driving license, 225 were randomly chosen to go to the driver sub-experiment, whereas others respondents with a car and a driving license took part in the passenger sub-experiment. The driver subsample ( 225 individuals) is much smaller than the passenger sub-sample (1 476 individuals) because the driver model needs a smaller amount of data to be calibrated. However, note that around $90 \%$ of the pooled sample has a driving license and a car in the household (see Table 1), meaning that driving a car is part of the choices set of most individuals.

The characteristics of the samples are displayed in Table 1. Individuals in the driver sample are on average richer, have higher skilled jobs, live closer to rail station but make less interurban trips than individuals from the passenger sample. The income information has been collected as a categorical variable with 6 categories: lower than $500 €, 500-1000 €, 1000-1500 €, 1500-2000 €, 2000-3000 €$, higher than $3000 €$. We turn this variable into a continuous variable by using the centers of the classes, ${ }^{7}$ because a continuous variable provides more readable results when introducing interaction effects.

individuals who received the email were selected among individuals registered with the Internet panel provider. The Internet panel provider also controls for the quality and the commitment of the replies by checking the length of time spent for each screen of the survey, and by asking consistency questions at the end of the survey.

${ }^{7}$ The centers of the lowest and highest classes are 250 and $4000 €$, respectively. 
The statistics on the number of long-distance trips are biased by surprising statements from few individuals in the passenger sample who stated several thousand interurban trips in the last year.

\begin{tabular}{|c|c|c|c|c|c|c|}
\hline & \multicolumn{2}{|c|}{ Driver } & \multicolumn{2}{|c|}{ Passenger } & \multicolumn{2}{|c|}{ Pooled } \\
\hline & Mean & sd & Mean & sd & Mean & sd \\
\hline Gender (1=woman) & $40.9 \%$ & & $51.4 \%$ & & $50.0 \%$ & \\
\hline Age (years) & 46.64 & 15.72 & 45.61 & 14.92 & 45.75 & 15.03 \\
\hline Income (categorical) (€/month) & 2302.22 & 1186.70 & 2029.81 & 1108.35 & 2065.84 & 1122.46 \\
\hline \multicolumn{7}{|l|}{ Occupation } \\
\hline Higher managerial and prof. occupations & $15.1 \%$ & & $10.0 \%$ & & $10.7 \%$ & \\
\hline Intermediate occupations & $13.3 \%$ & & $14.6 \%$ & & $14.5 \%$ & \\
\hline Employees & $22.7 \%$ & & $31.4 \%$ & & $30.2 \%$ & \\
\hline Routine occupations & $8.9 \%$ & & $6.0 \%$ & & $6.3 \%$ & \\
\hline Retired & $24.4 \%$ & & $19.9 \%$ & & $20.5 \%$ & \\
\hline Unemployed & $11.6 \%$ & & $13.3 \%$ & & $13.1 \%$ & \\
\hline Students & $4.0 \%$ & & $4.8 \%$ & & $4.7 \%$ & \\
\hline Access time (min.) to the closest rail station & 21.19 & 18.00 & 26.85 & 52.30 & 26.10 & 15.15 \\
\hline Is it a High speed rail station? (1=Yes) & $58.2 \%$ & & $63.5 \%$ & & $62.8 \%$ & \\
\hline Car in the household (1=Yes) & $100 \%$ & & $91 \%$ & & $92 \%$ & \\
\hline Car but no driving license (1=yes) & $0.0 \%$ & & $3.4 \%$ & & $2.9 \%$ & \\
\hline \multicolumn{7}{|c|}{ Mode-specific experience for interurban trips (at least one trip in the last year) } \\
\hline train $(1=$ Yes $)$ & $36.9 \%$ & & $42.5 \%$ & & $41.8 \%$ & \\
\hline bus (1=Yes) & $19.6 \%$ & & $20.1 \%$ & & $20.0 \%$ & \\
\hline carpooling as driver ( $1=$ Yes) & $38.7 \%$ & & $29.0 \%$ & & $30.3 \%$ & \\
\hline carpooling as passenger $(1=$ Yes $)$ & $29.8 \%$ & & $33.9 \%$ & & $33.4 \%$ & \\
\hline \multicolumn{7}{|l|}{ Number of interurban trips made } \\
\hline during the last year & 11.56 & 18.54 & 72.01 & 1438.27 & 64.01 & 1339.88 \\
\hline by train during the last year & 1.48 & 4.95 & 3.13 & 52.30 & 2.91 & 48.75 \\
\hline by bus during the last year & 1.31 & 10.39 & 19.53 & 655.33 & 17.12 & 610.46 \\
\hline by carpooling as driver & 3.46 & 9.67 & 5.55 & 50.65 & 5.27 & 47.32 \\
\hline by carpooling as passenger & 1.51 & 4.68 & 3.41 & 16.14 & 3.16 & 15.15 \\
\hline Sample size & \multicolumn{2}{|c|}{225} & \multicolumn{2}{|c|}{1476} & \multicolumn{2}{|c|}{1701} \\
\hline
\end{tabular}

Notes: The mean of categorical indicated the proportion of the sample in this category (for example, the proportion of female in the driver sample is $40.9 \%)$. Income variable is categorical, the mean and standard deviation have been computed by using the centers of the classes. The sum of interurban trips made by different modes during last year does not exactly matches the stated total of interurban trips made during last year, due to divergence between respondents' statements.

Table 1: Characteristics of the samples

\subsection{The stated choice experiments}

Respondents were first asked to fill in some socioeconomic characteristics and then take part in the driver sub-experiment or in the passenger sub-experiment, as described in subsection 2.1.

Each respondent faced two sets of 8 successive choice situations, and for each of these $8 \times 2=16$ situations he/she was asked to make a choice. The two sets of choice situations faced by the individual 
differ in the length of trips, because we wanted to test if our results depend on the distance of the trip. The length of the trips were $100 \mathrm{~km}, 300 \mathrm{~km}, 500 \mathrm{~km}$ and $700 \mathrm{~km}$. For example, an individual first faced 8 mode choice situations for a 300km trip, than 8 mode choice situations for a $700 \mathrm{~km}$ trip.

From the analysis perspective, it is important that the attribute levels of the proposed modes are not such that the preference for one mode strongly dominates the preferences for the other modes present (Hensher \& Rose, 2007). If a dominant alternative exists, respondents are unlikely to make a trade-off. We used the software Ngene $^{8}$ and a D-optimal design ${ }^{9}$ to build choice tasks described below. The efficient design allows to avoid strong dominance of one mode on another. For that, prior information about parameters should be used. Based on Wardman et al. (2012) and Quinet (2013), we set prior of $10 € /$ hour, $8 € / \mathrm{h}$ and $17 € / \mathrm{h}$ for travel time, schedule delay early and schedule delay late, respectively.

For each of the four possible trip distances $(100,300,500$ and $700 \mathrm{~km})$ and for the two sub-experiments (driver and passenger), we built 100 choice situations. For each respondent, 8 choice situations were randomly chosen among the set of 100 choice situations for one distance, and 8 choice situations were randomly chosen among the set of 100 choice situations for another distance.

Figure 1 presents examples of choice screens submitted to respondents.

\footnotetext{
${ }^{8}$ See www.choice-metrics.com.

${ }^{9} \mathrm{~A}$ D-optimal design minimizes the D-error measure. It produces the design with smallest asymptotic standard errors for each of the estimated parameters (Hensher \& Rose, 2007).
} 


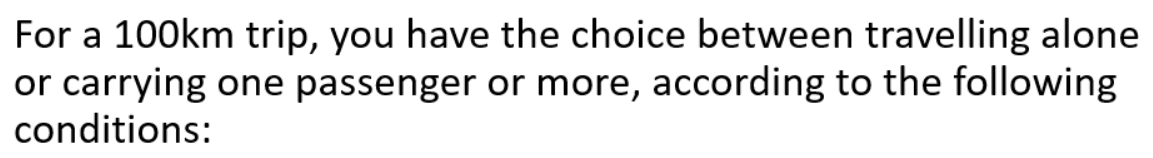

\begin{tabular}{|l|c|c|}
\hline & Alone & Carpool \\
\hline Travel time & 1 hour & $1: 25$ hour \\
\hline Carpool revenue & & 30 euros \\
\hline Nb of carpooled passengers & & 3 \\
\hline
\end{tabular}

\section{What do you choose?}

\section{Travel alone}

\section{Carpool}

Figure 1a: Example of choice situation screen submitted to respondent taking the driver survey

\begin{tabular}{|c|c|c|c|c|}
\hline & Train & Bus & Carpool A & Carpool B \\
\hline Travel time & 1:10 hour & 1:25 hour & 1:05 hour & 1:10 hour \\
\hline $\begin{array}{l}\text { Difference between the } \\
\text { scheduled arrival time and } \\
\text { your preferred arrival time }\end{array}$ & No & 1 hour later & 5 min later & 15 min earlier \\
\hline Price & 15 euros & 13 euros & 5 euros & 6 euros \\
\hline $\begin{array}{l}\text { Nb of other individuals in } \\
\text { the car }\end{array}$ & & & 3 & 2 \\
\hline
\end{tabular}

Which transport mode do you choose?
Train
Bus
Carpool A
Carpool B

Figure 1b: Example of choice situation screen submitted to respondent taking the passenger survey

We proposed two carpooling alternatives in the passenger survey to make the transport supply more realistic. Indeed, the observation of internet multimodal journey planners reveals the carpool supply is more complete along the day in the sense that it offers more possible departure times. ${ }^{10}$ For a specific trip with a specific desired arrival time, a passenger will likely find one well-fitting bus or train option,

\footnotetext{
${ }^{10}$ For example, we made a request on the website www.kelbillet.com (an online long distance mode comparator) on June 25th 2019 for a trip from Lyon to Paris on June 28th 2019. The results to this request were the following: 86 possible departures by carpool, 47 departures by bus, and 20 departures by train.
} 
but several well-fitting carpooling options. Carpools allows more flexibility in the departure time choice than train or bus whose frequencies are much lower.

\subsubsection{Drivers' survey}

Respondents reviewed two hypothetical alternatives, driving alone (solo) or driving with one or more passengers (carpool). The alternatives in each choice situation were described by three attributes: travel time, monetary gain (null if solo, positive in carpool), and number of carpooled people (null if solo, positive in carpool). Travel time is known as one the main determinant of mode choice. Shaheen et al. (2017) show that saving money is main motivation of carpool driver. We decided to consider the number of passengers as an attribute to test a conviviality effect between individuals. The characteristics of the attributes levels in the choice situations submitted to respondents as well as the respondents' choices frequency are displayed in Table 2.

\begin{tabular}{|c|c|c|c|c|c|c|}
\hline Distance & Attributes & Mean & sd & Levels & & \\
\hline & & & & Min & Max & Step size \\
\hline \multirow[t]{6}{*}{$100 \mathrm{~km}$} & Travel time alone (min.) & 74.68 & 10.23 & 60 & 90 & 5 \\
\hline & Travel time carpool (min.) & 74.87 & 10.29 & 60 & 90 & 5 \\
\hline & Carpool revenue $(€)$ & 25.46 & 13.87 & 5 & 50 & 5 \\
\hline & $\mathrm{Nb}$ of carpool passengers & 1.98 & 0.80 & 1 & 3 & 1 \\
\hline & Mode choice: carpool & $47 \%$ & & & & \\
\hline & $\mathrm{Nb}$ of choice situations proposed & 896 & & & & \\
\hline \multirow[t]{6}{*}{$300 \mathrm{~km}$} & Travel time alone & 198.53 & 33.67 & 150 & 250 & 20 \\
\hline & Travel time carpool & 199.00 & 34.28 & 150 & 250 & 20 \\
\hline & Carpool revenue & 57.34 & 27.94 & 20 & 100 & 20 \\
\hline & $\mathrm{Nb}$ of carpool passengers & 1.98 & 0.83 & 1 & 3 & 1 \\
\hline & Mode choice: carpool & $53 \%$ & & & & \\
\hline & $\mathrm{Nb}$ of choice situations proposed & 896 & & & & \\
\hline \multirow[t]{6}{*}{$500 \mathrm{~km}$} & Travel time alone & 341.58 & 51.45 & 270 & 420 & 30 \\
\hline & Travel time carpool & 345.96 & 50.88 & 270 & 420 & 30 \\
\hline & Carpool revenue & 84.48 & 39.38 & 30 & 150 & 20 \\
\hline & $\mathrm{Nb}$ of carpool passengers & 1.98 & 0.81 & 1 & 3 & 1 \\
\hline & Mode choice: carpool & $53 \%$ & & & & \\
\hline & $\mathrm{Nb}$ of choice situations proposed & 904 & & & & \\
\hline \multirow[t]{6}{*}{$700 \mathrm{~km}$} & Travel time alone & 474.54 & 50.23 & 400 & 550 & 30 \\
\hline & Travel time carpool & 474.57 & 51.41 & 400 & 550 & 30 \\
\hline & Carpool revenue & 78.78 & 34.18 & 40 & 200 & 20 \\
\hline & $\mathrm{Nb}$ of carpool passengers & 1.99 & 0.82 & 1 & 3 & 1 \\
\hline & Mode choice: carpool & $51 \%$ & & & & \\
\hline & $\mathrm{Nb}$ of choice situations proposed & 904 & & & & \\
\hline
\end{tabular}

Table 2: Characteristics of the drivers' choice situations submitted to respondents 


\subsubsection{Passengers' survey}

Respondents review four hypothetical alternatives: bus, train, carpool A or carpool B. Each alternative is described by at least four attributes: Travel time, Early arrival, Late arrival and Price (€). For the carpooling alternatives, the number of other individuals in the car is added as attribute. As for drivers, travel time and monetary cost attributes have been well identified as determinants of mode choice in the literature. Carpool passengers report flexibility in terms of possible departure and arrival times as an advantage of this mode over other passenger modes (ADEME, 2015a). These differences between modes in arrival times can be measured through schedule delay cost i.e. the time difference between the preferred arrival time and the real arrival time (Monchambert \& Proost, 2019). The $100 \mathrm{~km}$ choice situations are described in Table 3. Other distance choice situations descriptions are relegated to the appendices (see Tables 9, 10, 11 and 12).

\begin{tabular}{|c|c|c|c|c|c|c|}
\hline Mode & Variable & Mean & sd & Min & Max & Step size \\
\hline \multirow[t]{4}{*}{ Train } & Travel time (min.) & 60,19 & 14,14 & 40 & 80 & 10 \\
\hline & Early arrival (min.) & 31,71 & 42,98 & 0 & 120 & 15 \\
\hline & Late arrival (min.) & 21,41 & 28,82 & 0 & 90 & 15 \\
\hline & Price $(€)$ & 12,45 & 5,63 & 5 & 20 & 5 \\
\hline \multirow[t]{4}{*}{ Bus } & Travel time & 74,92 & 10,12 & 60 & 90 & 5 \\
\hline & Early arrival & 25,24 & 37,08 & 0 & 120 & 15 \\
\hline & Late arrival & 14,86 & 21,69 & 0 & 75 & 15 \\
\hline & Price & 8,33 & 4,10 & 2 & 15 & 1 \\
\hline \multirow[t]{5}{*}{ Carpool A } & Travel time & 74,76 & 10,06 & 60 & 90 & 5 \\
\hline & Early arrival & 7,55 & 11,27 & 0 & 30 & 5 \\
\hline & Late arrival & 5,71 & 9,13 & 0 & 30 & 5 \\
\hline & Price & 7,48 & 1,71 & 5 & 10 & 1 \\
\hline & $\mathrm{Nb}$ of other ind. & 1,99 & 0,82 & 1 & 3 & 1 \\
\hline \multirow[t]{5}{*}{ Carpool B } & Travel time & 74,65 & 10,02 & 60 & 90 & 5 \\
\hline & Early arrival & 7,02 & 10,69 & 0 & 30 & 5 \\
\hline & Late arrival & 5,72 & 9,40 & 0 & 30 & 5 \\
\hline & Price & 7,49 & 1,72 & 5 & 10 & 1 \\
\hline & $\mathrm{Nb}$ of other ind. & 2,00 & 0,82 & 1 & 3 & 1 \\
\hline \multicolumn{2}{|c|}{ Mode choice: train } & $28 \%$ & & & & \\
\hline \multicolumn{2}{|c|}{ Mode choice: bus } & $21 \%$ & & & & \\
\hline \multicolumn{2}{|c|}{ Mode choice: carpool A } & $29 \%$ & & & & \\
\hline \multicolumn{2}{|c|}{ Mode choice: carpool B } & $22 \%$ & & & & \\
\hline \multicolumn{2}{|c|}{$\mathrm{Nb}$ of choice situations proposed } & 5908 & & & & \\
\hline
\end{tabular}

Table 3: Characteristics of the $100 \mathrm{~km}$ passengers' choice situations submitted to respondent 


\section{Theoretical framework}

We use a stated choices experiment survey to model the long-distance mode choice. This allows to (i) test the validity of our hypothesis described in the introduction, and (ii) valuate the attributes of carpooling.

\subsection{Utility functions}

Some journey positive attributes stated by carpoolers are not included in traditional utility functions. Therefore we need to define new utility functions which take into account these attributes. We distinguish utility of a trip as a driver from utility of a trip as a passenger. For each of these two roles, we define one utility function per available mode. Two modes are available for a trip as a driver (solo and carpool), and three modes are available for a trip as a passenger (train, bus and carpool).

Travel time and monetary cost (or gain) are the traditional attributes of transport modes used in mode choice modelling (see for example Truong \& Hensher, 1985). The trade-off between these two attributes is conceptualized through the VoTT defined in subsection 2.2 below. These attributes are to be included in the utility functions to test if carpool choice implies a lower, equal or high VoTT than other transport modes. A specific attribute of carpool is the number of individuals in the car, which should also be considered in the carpool utility function. This attribute is somehow related to the occupancy rate in public transport, which may strongly deteriorate individual perceptions of trips (Haywood et al., 2017).

One of the purposes of the paper is to identify the ways individual socio-economics characteristics may have an effect on the mode choice probabilities. We want to test if these individual characteristics may explain the inter-individual differences in the VoTT and in the perception of the number of individuals in the car. Moreover, we especially want to test if the inter-modes variations in VoTT can be explained by socio-economics variables. For that, we use interaction effects between socio-economics variables and modes attributes of interest.

We consider three main socio-economic characteristics: age, gender and income. These variables have been identified from reviews of the literature as some of the main determinants of the distribution of VoTT (Fosgerau, 2006, Small, 2012) on the one hand, and also as determinants of carpooling choice on 
the other hand (see Correia \& Viegas (2011) and Neoh et al. (2017) among others). We recognize that these socio-economics variables are not solely determinant per se, but also because they are strongly correlated with other predictive variables that are more difficult to measure. For example, Scheiner (2014) shows that the effects of key events in life (such that birth of a child...) on travel mode choice depends on gender. In the same vein, Rosenbloom \& Burns (1993) find that women's travel decisions differ from men's because women have often fulfill multiple obligations, especially transportation or other need of children. Behind the age effect we can find the role of the complexity of trip chains. Older individuals prefer more homogenous trips, which can be more easily done with personal vehicle than with public transport (Su \& Bell, 2009).

The utility of a trip as a driver $(D)$ who is alone (i.e. solo or $s$ ) in his/her car, $U_{s}^{D}$, is usual and defined by:

$$
U_{s}^{D}=\beta_{0 ; s}+\beta_{1 ; s} t t_{s}+\sum_{i}\left(\gamma_{i ; s} X_{i}+\delta_{i ; s} X_{i} t t_{s}\right)+\sum_{k}\left(\gamma_{k ; s} X_{k}\right)+\varepsilon_{s}
$$

where $t t_{s}$ is the travel time solo, $X_{i}$ is a set of socio-economic characteristics from which we test the interaction with travel time (age, gender and income), and $X_{k}$ is a set of other individual characteristics.

A driver who chooses to carpool experiences a different utility, mainly because he/she is not alone in his/her car and because he/she receives a monetary payment. Therefore, his/her utility for a trip as a carpooling driver (i.e. carpool as a driver or $c p d$ ), $U_{c p d}^{D}$, is described by

$$
\begin{aligned}
U_{c p d}^{D}=\beta_{0 ; c p d}+ & \beta_{1 ; c p d} t t_{c p d}+\beta_{2 ; c p d} \tau+\beta_{3 ; c p d} N b E x t \text { Pass } \\
& +\beta_{4 ; c p d} N b E x t P a s s t t_{c p d} \\
& +\sum_{i}\left(\gamma_{i ; c p d} X_{i}+\delta_{i ; c p d} X_{i} t t_{c p d}+\theta_{i ; c p d} X_{i} N b E x t P a s s\right) \\
& +\sum_{k}\left(\gamma_{k ; c p d} X_{k}\right)+\varepsilon_{c p d}
\end{aligned}
$$

where $\tau$ is the (gross) monetary gain received by the carpool driver, and NbExtPass is the number of extra carpooled passengers in the car. The effect of the number of passengers has to be disentangled 
from the pure effect of carpool. Carpool is characterized by at least one passenger. Therefore, the variable Number of extra passengers contains the total number of carpooled passengers minus 1 .

Making a trip as a passenger differs from a trip as driver because a passenger may use different modes: carpool as passenger $(c p p)$, bus $(b)$ or train $(t)$. These modes being characterized by exogenous and discrete departure time and arrival time at destination, passengers have to choose within a finite set of possible arrival times. If the effective arrival time does not coincide with the preferred arrival time, the traveler incurs schedule delay costs, which can be early if he/she arrives before his/her preferred arrival time, or late if he/she arrives after (see Tseng \& Verhoef, 2008). The utility of a carpool passenger, $U_{c p p}^{P}$, is:

$$
\begin{aligned}
U_{c p p}^{P}=\beta_{0 ; c p p}+ & \beta_{1 ; c p p} t t_{c p p}+\beta_{2 ; p} r+\beta_{3 ; c p p} \text { NbOthPass }+\beta_{4 ; c p p} N b \text { OthPass } t t_{c p p} \\
& +\sum_{i}\left(\gamma_{i ; c p p} X_{i}+\delta_{i ; c p p} X_{i} t t_{c p p}+\theta_{i ; c p p} X_{i} \text { NbOthPass }\right) \\
& +\sum_{k}\left(\gamma_{k ; c p p} X_{k}\right)+\alpha_{1} \text { SchedEarly }+\alpha_{2} \text { SchedLate }+\varepsilon_{c p p},
\end{aligned}
$$

where $r$ is the monetary price paid by passengers, NbOthPass is the number of other passengers in the car (excluding the driver), SchedEarly and SchedLate are schedule delay time variables. Early (respectively late) schedule delay time is positive and equals the time between preferred and effective arrival times if the effective arrival time occurs before (resp. after) the preferred arrival, and equals zero if not.

A passenger choosing to travel by bus (i.e. $b$ ) or train (i.e. $t$ ) experiences the following utility:

$$
\begin{aligned}
U_{j}^{P}= & \beta_{0 ; j}+\beta_{1 ; j} t t_{j}+\beta_{2 ; p} r+\sum_{i}\left(\gamma_{i ; j} X_{i}+\delta_{i ; j} X_{i} t t_{j}\right)+\sum_{k}\left(\gamma_{k ; j} X_{k}\right) \\
& +\alpha_{1} \text { SchedEarly }+\alpha_{2} \text { SchedLate }+\varepsilon_{j}, \quad j=b, t .
\end{aligned}
$$

\subsection{Values of travel time and of other passengers in the car}

The Value of Travel Time (denoted VoTT) is the marginal rate of substitution between travel time and money (DeSerpa, 1971). Formally, it can be defined as (Lam \& Small, 2001): 


$$
V o T_{m} \equiv \frac{\frac{\partial U_{m}}{\partial t t_{m}}}{\frac{\partial U_{m}}{\partial p_{m}}}
$$

where $U_{m}$ is the utility associated to a trip with mode $m, t t_{m}$ is the travel time in mode $m$ and $p_{m}$ is a measure of monetary cost (or benefit) when using mode $m$. Consequently, the Value of Travel Time (VoTT) for each of the five modes we study can be written: ${ }^{11}$

$$
\begin{aligned}
& \operatorname{VoTT}_{s}=\frac{\beta_{1 ; s}+\sum_{i} \delta_{i ; s} X_{i}}{\beta_{2 ; c p d}}, \\
& \operatorname{VoTT}_{c p d}=\frac{\beta_{1 ; c p d}+\beta_{4 ; c p d} N b E x t P a s s+\sum_{i} \delta_{i ; c p d} X_{i}}{\beta_{2 ; c p d}}, \\
& \operatorname{VoTT}_{c p p}=\frac{\beta_{1 ; c p p}+\beta_{4 ; c p p} N b O t h P a s s+\sum_{i} \delta_{i ; c p d} X_{i}}{\beta_{2 ; p}}, \\
& \operatorname{VoTT}_{j}=\frac{\beta_{1 ; j}+\sum_{i} \delta_{i ; j} X_{i}}{\beta_{2 ; p}}, \quad j=b, t .
\end{aligned}
$$

The coefficients associated with the interaction terms, $\delta_{i}$, allow to measure how VoTT reacts to changes in individuals characteristics $\left(\frac{\partial V O T_{n}}{\partial X_{i}}=\frac{\delta_{i ; n}}{\beta_{2}}\right)$.

At this point, it might be useful to recall that we expect VoTT to vary across individuals, but that we also expect VoTT of one individual to vary across modes. These variations are due to differences in comfort, noise, safety... More generally, the conditions of travel have an impact on the marginal utility of time. Wardman (2004) refer to these differences as User Type variation and Mode Valued variation in VoTT. Therefore, we have to use varying choice attributes in the calculations of VoTT in Equation (6), and of VoEP and VoOP in Equation (7) below.

The other coefficients of interest to understand attitudes towards carpooling are related to the number of people in the car. In the same vein as VoTT, we define the Value of an Extra Passenger (VoEP) for carpool driver and the Value of an Other Passenger ( $V o O P)$ for carpool passenger:

\footnotetext{
${ }^{11}$ There is no monetary value in the utility function of a driver solo (Equation (1)). Therefore we use the coefficient $\beta_{2 ; p}$ present in Equation (2). There is no normalization problem as coefficients from Equations (1) and (2) will be simultaneously estimated in a binomial logit model.
} 


$$
\begin{aligned}
& V o E P_{c p d}=\frac{\beta_{3 ; c p d}+\beta_{4 ; c p d} t t_{c p d}+\sum_{i} \theta_{i ; c p d} X_{i}}{\beta_{2 ; d}}, \\
& V o O P_{c p p}=\frac{\beta_{3 ; c p p}+\beta_{4 ; c p p} t t_{c p p}+\sum_{i} \theta_{i ; c p d} X_{i}}{\beta_{2 ; p}} .
\end{aligned}
$$

If VoEP and VoOP are positive, then people value the fact to travel with additional individuals in the car. This is the expected result according to declarative surveys made in France (ADEME, 2015a).

\subsection{Mixed logit}

We estimate coefficients in Equations (1), (2), (3) and (4) in a logit framework (McFadden 1974). Utility functions in Equations (1), (2), (3) and (4) can be re-written:

$$
\begin{array}{cc}
U_{m}^{D}=V_{m}^{D}+\varepsilon_{m}, & m=c p d, s, \\
U_{m}^{P}=V_{m}^{P}+\varepsilon_{m}, & m=c p p, b, t .
\end{array}
$$

$V_{m}$ is the deterministic part of the utility, and $\varepsilon_{m}$ the stochastic part. In this study, drivers have to choose between two transport modes: travelling alone or carpooling. Passengers may choose to travel by bus, train, or to carpool.

We use a mixed logit model (Hensher \& Greene, 2003) to take into account the panel structure of our data. Each individual in our sample face a number of exercises or choice sets. Consequently, the choices made by one individual are not independent. We control this dependency by considering that the intercept in utility function $\left(\beta_{0, m}\right)$ are normally distributed across individuals. The mean and the standard deviation of these normal distributions measure the variation of preference (or taste) for one mode over another mode across individuals, other things being equal.

In a context of a number $T$ of choice situations and assuming that the errors terms $\varepsilon_{m}$ are identically and independently extreme value distributed over individual, alternatives, and choice situations, Train (2009) shows that the probability of an individual selecting mode $m$ is given by

$$
P_{m}^{D}=\int \prod_{t=1}^{T}\left[\frac{1}{1+e^{V_{m}^{D}-V_{-m}^{D}}}\right] f\left(\beta_{0}\right) d \beta_{0}, \quad m=c p d, s,
$$




$$
P_{m}^{P}=\int \prod_{t=1}^{T}\left[\frac{e^{V_{m}^{P}}}{\sum_{k} e^{V_{k}^{D}}}\right] f\left(\beta_{0}\right) d \beta_{0}, \quad m=c p p, b, t
$$

\section{Results}

Results are split in two subsections. Subsection 4.1 focuses on drivers' results and 4.2 on passengers' results.

We use mixed logit models to take into account the panel structure of our data. Therefore the intercepts $\beta_{0, m}$ in Equations (1), (2), (3) and (4) are assumed to be normally distributed. ${ }^{12}$ We focus on the socioeconomic variables affecting VoTT and value of an extra passenger, and not on the computation of VoTT to perform cost-benefit analysis. Consequently, we do not estimate random parameters for travel time or other variables.

The models have been estimated with the mlogit package built by Croissant (2012) for the R software.

\subsection{Drivers' results}

Table 4 shows results of binomial mixed logit estimations of a model combining Equations (1) and (2) and described in Equation (9). ${ }^{13}$ The reference mode is driving solo. We estimate four different specifications. In the first one (col. (1) in Table 4), we estimate an "average" cost of time for a trip as driver by assuming there is no difference between parameters associated with travel time solo and with travel time carpool as a driver $\left(\beta_{1 ; s}=\beta_{1 ; c p d}\right)$. In the second one (col. (2)), we introduce individual effects (age, gender, income, access time to the closest rail station) and interaction effects between travel time, the number of extra passengers and three socio-economic variables: age, gender and income. We repeat the exercise in specifications (3) and (4) but we differentiate the effect of travel time on utility depending if the trip is made as a solo driver or as a carpool driver $\left(\beta_{1 ; s} \neq \beta_{1 ; c p d}\right)$. The reference mode is "solo", so generally a negative (resp. positive) coefficient implies a negative (resp. positive) marginal effect of the variable on the probability of choosing carpool over solo. The interpretation of the travel

\footnotetext{
${ }^{12}$ We tested other distributions such that uniform, triangular or lognormal. The normal distribution always produces the best goodness of fit.

${ }^{13}$ For ease of exposition, standard errors are not reported. The full results table is available in the appendices (see Table 13).
} 
time coefficients is different because they are mode-specific, so a negative (resp. positive) coefficient implies a negative (resp. positive) marginal effect of the variable on the probability of choosing this specific mode over the other.

\begin{tabular}{|c|c|c|c|c|}
\hline & (1) & (2) & (3) & (4) \\
\hline Intercept - mean & $-1.160^{* * * *}$ & 0.216 & $-0.969^{* * *}$ & $1.354^{* * *}$ \\
\hline Intercept - sd & $3.776^{* * *}$ & $3.640^{* * * *}$ & $3.807^{* * * *}$ & $3.714^{* * *}$ \\
\hline Gain from carpooling (euros) & $0.016^{* * *}$ & $0.019^{* * * *}$ & $0.021^{* * *}$ & $0.021^{* * *}$ \\
\hline \multicolumn{5}{|l|}{ Travel time effects } \\
\hline Travel time (hours) & $-0.859^{* * *}$ & $-1.253^{* * *}$ & & \\
\hline Trav. Time x Age & & $0.016^{* * *}$ & & \\
\hline Trav. Time x Gender & & 0.022 & & \\
\hline Trav. Time x Income & & $-0.137^{* * *}$ & & \\
\hline \multicolumn{5}{|l|}{ Travel time solo effects } \\
\hline Travel Time solo (hours) & & & $-0.815^{* * *}$ & $-1.069^{* * *}$ \\
\hline TT solo x Age & & & & $0.012^{* * * *}$ \\
\hline TT solo $x$ Gender & & & & 0.007 \\
\hline TT solo $x$ Income & & & & $-0.140^{* * *}$ \\
\hline \multicolumn{5}{|l|}{ Travel time carpool effects } \\
\hline Travel Time carpool (hours) & & & $-0.923^{* * *}$ & $-1.445^{* * *}$ \\
\hline TT carpool x Age & & & & $0.018^{* * *}$ \\
\hline TT carpool x Gender & & & & 0.049 \\
\hline TT carpool x Income & & & & $-0.139^{* * *}$ \\
\hline \multicolumn{5}{|l|}{ Number of extra passengers effects } \\
\hline $\mathrm{Nb}$ of extra pass. & $-0.198^{* * * *}$ & $0.425^{*}$ & $-0.190^{* * *}$ & 0.216 \\
\hline $\mathrm{Nb}$ of extra pass. $\mathrm{x} T \mathrm{TT}$ & & $-0.072^{* * * *}$ & & -0.034 \\
\hline $\mathrm{Nb}$ of extra pass. $\mathrm{x}$ Age & & -0.006 & & -0.005 \\
\hline $\mathrm{Nb}$ of extra pass. $\mathrm{x}$ Gender & & $0.468^{* * *}$ & & $0.470^{* * * *}$ \\
\hline $\mathrm{Nb}$ of extra pass. $\mathrm{x}$ Income & & -0.095 & & -0.090 \\
\hline \multicolumn{5}{|l|}{ Individual effects } \\
\hline Age (years) & & $-0.023^{* * *}$ & & $-0.044^{* * *}$ \\
\hline Gender $(0=\mathrm{M} ; 1=\mathrm{F})$ & & $-1.262^{* * *}$ & & $-1.644^{* * *}$ \\
\hline Income ( $\mathrm{k}$ euros) & & $0.354^{* * *}$ & & $0.548^{* * * *}$ \\
\hline Access time to closest rail station (min.) & & $-0.028^{* * * *}$ & & $-0.030^{* * *}$ \\
\hline AIC & 2957.585 & 2916.555 & 2941.750 & 2902.061 \\
\hline Log Likelihood & -1473.792 & -1442.277 & -1464.875 & -1431.031 \\
\hline McFadden R2 & 0.409 & 0.422 & 0.423 & 0.426 \\
\hline Num. obs. & 3600 & 3600 & 3600 & 3600 \\
\hline Sample size & 225 & 225 & 225 & 225 \\
\hline
\end{tabular}

Notes. This table reports binomial mixed logit estimations of Eq. (1) and (2) where the intercepts $\beta_{0} \sim \mathcal{N}(\mu, \sigma), \beta_{1 ; s}=\beta_{1 ; c p d}$ (columns (1) and (2)), $\gamma_{i}=0$ (columns (1) and (3)) and $\delta_{i}=\theta_{i}=0$ (columns (1), (2), and (3)). The dependent variable is the mode choice between "solo" and "carpool". The reference alternative is "solo". ***p $<0.01, * * \mathrm{p}<0.05, * \mathrm{p}<0.1$.

Table 4: Empirical results from the drivers' model 
The Akaike Information Criterion (AIC) confirms that using interaction effects and differentiated travel time coefficients in specification (4) produces the best goodness of fit. ${ }^{14}$

The intercept mean in the first specification is negative and shows that other thing being equal, on average, respondents have a strong preference for driving solo over carpooling. The average monetary benefit from carpooling needed to compensate this aversion for carpooling is 72.5 euros $(-1.160 / 0.016=-72.5)$. $)$. However, the intercepts standard deviations are large and significant in all specification. This means that the preference (or aversion) for one mode over another is considerably spread among the population. The intercept mean switches sign and becomes positive in specification (4) which includes individual effects. This means that the preference for driving solo over carpooling is strongly correlated with socio-economic characteristics (Age, Gender and Income). The reading of these coefficients should be made cautiously as these three variables are also tested as interaction variables with Travel time and Number of extra passengers effects in the model.

As expected, the Gain from carpooling coefficient sign is positive in all specifications. The values of the estimated coefficients mean that other things being equal, a 1 euro increase in the gain from carpooling raises the odds of carpooling over driving solo by around $2 \% .{ }^{15}$

We find that travel time decreases utility of a trip as a driver, even when carpooling, because all the estimated coefficients associated with travel time are negative in all specifications. The coefficient associated with travel time alone is always less negative than the one associated with carpool travel time. ${ }^{16}$ This implies that on average the negative effect of travel time on driver's utility is larger when driving a carpooler than when driving solo. On the opposite of carpoolers' statements from previous French survey (ADEME, 2015a), we find that on average individuals prefer driving solo to taking passengers. Coefficients associated with the interactions effects between travel time and age on the one

\footnotetext{
${ }^{14}$ This is confirmed by the LR Tests and Wald Tests we conducted.

${ }^{15} \exp (0.016)=1.016$, and $\exp (0.21)=1.021$.

${ }^{16}$ We test the difference between the coefficients with a Wald test. The Chi-squared statistics equals 17.9 in specification (3) and 21.9 in specification (4). The difference between coefficients $\beta_{1, s}$ and $\beta_{1, c p d}$ is statistically significant in the two specifications.
} 
hand, and income on the other hand are respectively positive and negative. The utility of a trip whether solo or carpool decreases faster with travel time if the driver is younger and richer.

We introduced the access time to the closest rail station as an explanatory variable because rail stations are often multimodal platforms that are also used as carpooling meeting or exiting points. ${ }^{17}$ Individuals living further away from rail station have a lower probability to carpool, which is confirmed by the estimated coefficients.

The effect of the number of carpooled passengers is tricky. Whereas specifications (1) and (3) suggest a negative effect of the number of extra passengers, specifications (2) and (4) show that a strong gender effect is playing. This effect is illustrated in Table 5. This table displays carpool choice probability of the representative ${ }^{18}$ driver as a function of gender, number of carpooled passenger and travel time, in a situation of an $80 €$ carpool monetary gain. ${ }^{19}$ The gender effect is twofold: females have a greater dislike for carpooling than males (the difference in carpool choice probability is always larger than 20 percentage points), however, they prefer conveying two passengers to conveying one passenger, whereas it is the opposite for males. The first effect has been documented in the literature (de Luca \& Pace, 2015, Becker et al., 2017), but the second one is, at the best of our knowledge, new.

\begin{tabular}{llcc}
\hline \multirow{2}{*}{ Travel time } & \multirow{2}{*}{ Nb of passenger } & \multicolumn{2}{c}{ Gender } \\
& & Male & Female \\
\hline \multirow{2}{*}{2 hours } & 1 passenger & $76 \%$ & $39 \%$ \\
& 2 passengers & $70 \%$ & $43 \%$ \\
5 hours & 1 passenger & $51 \%$ & $17 \%$ \\
& 2 passengers & $41 \%$ & $18 \%$ \\
\hline Notes. This table & reports carpool choice probability of the \\
representative driver having the choice between driving solo or \\
carpooling with a monetary gain of $80 €$.
\end{tabular}

Table 5: Carpool choice probability of the representative driver as a function of the gender, number of carpooled passenger and travel time

\footnotetext{
${ }^{17}$ This variable could also be correlated with other aspects that can vary depending on distance from closest rail station.

${ }^{18}$ The representative driver is someone who has all the characteristics of the driver sample average.

${ }^{19}$ The amount of $80 €$ has been chosen such that the carpool probability is significantly larger than 0 .
} 
We use the coefficient associated with the Gain from carpooling to compute monetary values of travel time (VoTT) and values of an extra passenger (VoEP), as defined in Equations (6) and (7). ${ }^{20}$ These figures are exposed in Table 6.

\begin{tabular}{|c|c|c|c|c|}
\hline Specification & (1) & (2) & (3) & (4) \\
\hline VoTT (euros/hour) & 53.25 & 42.45 & & \\
\hline Marginal effect of Age (years) on VoTT (euros/h) & & -0.81 & & \\
\hline Marginal effect of Income (k euros) on VoTT (euros/h) & & 7.05 & & \\
\hline Solo VoTT (euros/hour) & & & 39.48 & 38.3 \\
\hline Marginal effect of Age (years) on alone VoTT (euros/h) & & & & -0.58 \\
\hline Marginal effect of Income (k euros) on alone VoTT (euros/h) & & & & 6.56 \\
\hline Carpool VoTT (euros/hour) & & & 44.71 & 43.1 \\
\hline Marginal effect of Age (years) on carpool VoTT (euros/h) & & & & -0.86 \\
\hline Marginal effect of Income (k euros) on carpool VoTT (euros/h) & & & & 6.51 \\
\hline Carpool VoTT / Solo VoTT & & & $113 \%$ & $113 \%$ \\
\hline Value of extra passenger (euros) & -12.26 & -10.44 & -9.22 & -9.64 \\
\hline Marginal effect of Travel time (min.) on value of extra pass. (euros) & & -0.06 & & \\
\hline Marginal effect of gender $(0=\mathrm{M} ; 1=\mathrm{F})$ on value of extra pass. (euros) & & 24.03 & & 22.03 \\
\hline
\end{tabular}

Table 6: Drivers' values of travel time and of extra passenger

Computed VoTT are above $38 € /$ hour in specification (4) which has the best goodness-of-fit. We also compute ration of carpool VoTT on solo VoTT. When taking into account the individual effects and the number of extra passenger in the car, we find carpool increases the VoTT by $13 \%$ with respect to solo VoTT. ${ }^{21}$ This percentage only reflects the difference in the cost of time, but does not include perceptions of carpooling which are not related to travel time.

We also find that the effect of income on VoTT is of same magnitude for carpool and driving alone (+6.5 euro/h when the income increases by 1000 euros), whereas the effect of age on VoTT is lower for driving alone than for carpooling (-0.58 euro/hour per year vs -0.86 euro/hour per year). We find that on average extra passenger lowers the utility of driver by around 10 euros. However, one has to be cautious with this result as it is very gender-dependent as shown by the marginal effect of gender and

\footnotetext{
${ }^{20}$ As we introduce interaction effects in specification (4), VoTT and VoEP must be computed by taking into account the age, the income, the gender, the number of extra passengers for VoTT and the travel time for VoEP. We take the values at the sample mean i.e. the representative driver making the representative trip to compute average values.

$21 \frac{\text { Carpool VoTT }}{\text { Solo VoTT }}=113 \%$ in specifications (3) and (4).
} 
results from Table 5. An extra passenger increases the utility of a trip by more than $20 €$ for a female driver.

\subsection{Passengers' results}

In each of the 16 choice situations they faced, individuals in the passenger experiment were asked to make a choice between 4 modes (train, bus, carpool A and carpool B). Our passenger discrete choice experiment contains two alternatives describing the same mode, carpool. In theory, estimated corresponding coefficients should be equal for these two alternatives. Therefore we constrained the model calibration to estimate equal coefficients for these two alternatives.

Table 6 displays results of mixed multinomial logit estimations of a model combining Equations (3) and (4) described in Equation (9). ${ }^{22}$ Four different specifications are estimated. The strategy is very similar to the one used for the drivers model. In the first specification (col. (1) in Table 4), we estimate an "average" cost of time for passengers $\left(\beta_{1 ; c p p}=\beta_{1 ; b}=\beta_{1 ; t}\right)$. In the second one (col. (2)), we introduce individual effects and we consider the interaction effects between travel time, the number of extra passengers, and three socio-economic variables: gender, age and income. We repeat the exercise in specifications (3) and (4) but we differentiate the effect of travel time on utility depending on the transport mode $\left(\beta_{1 ; c p p} \neq \beta_{1 ; b} \neq \beta_{1 ; t}\right)$. The reference mode is "train", so generally a negative (resp. positive) coefficient associated with another mode ("bus" or "carpool") implies a negative (resp. positive) marginal effect of the variable on the probability of choosing this mode over train. Let us recall that the interpretation of the price and travel time coefficients is different because they are modespecific. A negative (resp. positive) coefficient implies a negative (resp. positive) marginal effect of the variable on the probability of choosing this specific mode over the others.

22 Again, for ease of exposition, standard errors are not reported. The full results table is available in the appendices (see Table 14). 


\begin{tabular}{|c|c|c|c|c|}
\hline & (1) & (2) & (3) & (4) \\
\hline Price (euros) & $-0.027^{* * *}$ & $-0.027^{* * *}$ & $-0.028^{* * *}$ & $-0.029^{* * *}$ \\
\hline \multicolumn{5}{|l|}{ Travel time effects } \\
\hline Travel time (hours) & $-0.695^{* * *}$ & $-0.668^{* * *}$ & & \\
\hline TT x Age & & $0.003^{* * *}$ & & \\
\hline TT x Gender & & $-0.121^{* * *}$ & & \\
\hline TT x Income & & $-0.030^{* * *}$ & & \\
\hline \multicolumn{5}{|l|}{ Travel time train effects } \\
\hline Travel time train & & & $-0.473^{* * *}$ & $-0.535^{* * *}$ \\
\hline TT train $\mathrm{x}$ Age & & & & $0.003^{*}$ \\
\hline TT train $x$ Gender & & & & $-0.107^{* *}$ \\
\hline TT train x Income & & & & -0.009 \\
\hline \multicolumn{5}{|l|}{ Travel time carpool effects } \\
\hline Travel time carpool & & & $-0.736^{* * *}$ & $-0.728^{* * *}$ \\
\hline TT carpool x Age & & & & $0.003^{* * *}$ \\
\hline TT carpool x Gender & & & & $-0.134^{* * *}$ \\
\hline TT carpool x Income & & & & $-0.027^{* *}$ \\
\hline \multicolumn{5}{|l|}{ Travel time bus effects } \\
\hline Travel time bus & & & $-0.587^{* * *}$ & $-0.629^{* * *}$ \\
\hline TT bus x Age & & & & $0.003^{* * *}$ \\
\hline TT bus x Gender & & & & $-0.093^{* * *}$ \\
\hline TT bus x Income & & & & -0.018 \\
\hline \multicolumn{5}{|l|}{ Number of carpool passengers effects } \\
\hline $\mathrm{Nb}$ of other pass. & $-0.122^{* * *}$ & 0.015 & $-0.124^{* * *}$ & $-0.183^{* * *}$ \\
\hline $\mathrm{Nb}$ of pass. $\mathrm{x}$ TT & & $-0.051^{* * *}$ & & -0.003 \\
\hline $\mathrm{Nb}$ of pass. $\mathrm{x}$ Age & & 0.001 & & 0.001 \\
\hline $\mathrm{Nb}$ of pass. $\mathrm{x}$ Gender & & 0.019 & & 0.023 \\
\hline $\mathrm{Nb}$ of pass. $\mathrm{x}$ Income & & 0.005 & & 0.005 \\
\hline \multicolumn{5}{|l|}{ Individual effects - carpool } \\
\hline Intercept carpool - mean & $-0.406^{* * *}$ & -0.173 & $0.275^{* * *}$ & $0.323^{*}$ \\
\hline Intercept carpool - sd & $2.736^{* * *}$ & $2.764^{* * *}$ & $2.824^{* * *}$ & $2.837^{* * *}$ \\
\hline Age - carpool (years) & & $-0.011^{* * *}$ & & $-0.010^{* * *}$ \\
\hline Gender - carpool $(0=\mathrm{M} ; 1=\mathrm{F})$ & & $0.524^{* * *}$ & & $0.633^{* * *}$ \\
\hline Income - carpool ( $\mathrm{k}$ euros) & & $0.060^{* *}$ & & $0.119^{* * *}$ \\
\hline Access time to clos. rail st. - carpool (min) & & $-0.000^{* *}$ & & $-0.000^{* *}$ \\
\hline High speed station - carpool $(0=\mathrm{N} ; 1=\mathrm{Y})$ & & $-0.235^{* * *}$ & & $-0.212^{* * *}$ \\
\hline \multicolumn{5}{|l|}{ Individual effects - bus } \\
\hline Intercept bus - mean & $-0.318^{* * *}$ & $-0.515^{* * *}$ & $-0.245^{* * *}$ & $-0.364^{*}$ \\
\hline Intercept bus - sd & $2.221^{* * *}$ & $2.166^{* * *}$ & $2.211^{* * *}$ & $2.171^{* * *}$ \\
\hline Age - bus (years) & & $0.010^{* * *}$ & & $0.010^{* * *}$ \\
\hline Gender - bus $(0=\mathrm{M} ; 1=\mathrm{F})$ & & $-0.104^{*}$ & & $-0.179^{*}$ \\
\hline Income - bus (k euros) & & $-0.083^{* * *}$ & & -0.065 \\
\hline Access time to clos. rail st. - bus (min.) & & $-0.005^{* * *}$ & & $-0.005^{* * *}$ \\
\hline High speed station - bus $(0=\mathrm{N} ; 1=\mathrm{Y})$ & & -0.001 & & -0.013 \\
\hline \multicolumn{5}{|l|}{ Schedule delay effects } \\
\hline Early schedule delay (hours) & $0.101^{* * *}$ & $0.088^{* * *}$ & $0.058^{* * *}$ & $0.058^{* * *}$ \\
\hline Late schedule delay (hours) & $-0.360^{* * *}$ & $-0.372^{* * *}$ & $-0.414^{* * *}$ & $-0.417^{* * *}$ \\
\hline AIC & 49328.623 & 49126.464 & 48873.065 & 48805.539 \\
\hline Log Likelihood & -24655.311 & -24537.232 & -24425.532 & -24368.769 \\
\hline McFadden R2 & 0.231 & 0.235 & 0.238 & 0.240 \\
\hline Num. obs. & 23616 & 23616 & 23616 & 23616 \\
\hline Sample size & 1476 & 1476 & 1476 & 1476 \\
\hline
\end{tabular}

Notes. This table reports mixed multinomial logit estimations of Eq. (3) and (4) where the intercepts $\beta_{0} \sim \mathcal{N}(\mu, \sigma), \beta_{1 ; c p p}=\beta_{1 ; b}=\beta_{1 ; t}$ (columns (1) and (3)), and $\gamma_{i}=\delta_{i}=\theta_{i}=0$ (columns (1) and (3)). The dependent variable is the mode choice between "bus", "train", "carpool A", and "carpool B". The reference alternative is "train". Standard errors in parentheses. $* * * p<0.01, * * p<0.05, * p<0.1$.

Table 7: Empirical results from the passengers' model 
AIC reveals that specification (4) produces the best goodness of fit. The AIC ranking between models has been confirmed by LR Tests and Wald Tests we conducted.

The sign of the carpool intercept mean is negative in specification (1) and positive in specification (3). We cannot conclude for preference or aversion for carpool over train. However, the bus intercept mean is always negative. Passengers on average prefer train over bus. Note that standard deviations are large and significant for all modes in the four specification, showing a high variability in mode preference between individuals.

As expected, the sign of the coefficient associated with the price coefficient is negative. It implies that other things being equal, a 1 euro increase in the price of a mode decreases the odds of choosing this mode over other modes by $2.76 \%(\exp (-0.028)-1=-0.0276)$.

All coefficients associated with travel time are negative: whatever the mode, an increase in travel time decreases the probability of the mode to be chosen, other things being equal. Results of specifications (2) and (4) show that this negative effect of travel time on utility is on average higher for female, younger and wealthier individuals. When differentiating the effect of travel time by mode in specifications (3) and (4), we show that the negative effect of an extra minute of travel time on the mode choice probability is larger for carpool than for bus, and larger for bus than for train. ${ }^{23}$ This is a mode-specific variation which might be related to the comfort or to the use of time during a trip. However, coefficients estimated in specification (4) associated with the interaction between time and socio-economic variables are not statistically different from one mode to another.

Table 7 reveals that there is a clear other passenger effect: when carpooling, passengers prefer travelling alone with the driver than with another passenger. This effect is robust to all specifications except specification (2), however we cannot conclude on potential interaction effects with socio-economics variables.

\footnotetext{
${ }^{23}$ We compared the coefficients with Wald tests. The Chi-squared statistics for a test $\beta_{1, c p p}=\beta_{1, b}$ equals 294 in specification (3) and 10 in specification (4), and for a test $\beta_{1, t}=\beta_{1, b}$ it equals 45.3 in specification (3) and 2.4 in specification (4). The differences between coefficients are statistically significant at a $0.1 \%$ threshold, except the difference between $\beta_{1, t}$ and $\beta_{1, b}$ which is only significant at a $12 \%$ threshold.
} 
The analysis of individual effects shows that age, gender and income effects are also drivers of the probability of choosing carpool over train. Specifications (2) and (4) reveal that older individuals, females and wealthier individuals have a higher preference for carpool over train.

Coefficients associated with schedule delay are not easy to interpret. As expected, individuals prefer to arrive at destination earlier than later. However, they also prefer to arrive earlier than on time. They seem to set up a buffer time to anticipate potential unreliability of travel times.

Table 8 reports monetary value of the attributes of passenger transport modes as defined in Equation (6) and (7). Train VoTT are close from previous results in the literature: Abrantes \& Wardman (2011) found a rail VoTT of $13 € /$ hour for 200 miles trips. ${ }^{24}$ The VoTT to be used in CBA analysis in France is 15.7 $€ /$ hour, independently of the mode (Quinet, 2013). We find that the VoTT is lower for passengers in any mode than for drivers. A potential explanation is that the drivers VoTT have been estimated through willingness to accept method whereas passengers VoTT have been estimated through willingness to pay survey.

\footnotetext{
${ }^{24}$ They find a value of in-vehicle time of 19 pence/minute in Q4 2008 prices for 200 miles trips.
} 


\begin{tabular}{|c|c|c|c|c|}
\hline Specification & (1) & (3) & (4) & (6) \\
\hline VoTT (euros/hour) & 25.9 & 26.5 & & \\
\hline Marginal effect of Gender $(0=\mathrm{M} ; 1=\mathrm{F})$ on VoTT $($ euros $/ \mathrm{h})$ & & 4.48 & & \\
\hline Marginal effect of Age (years) on VoTT (euros/h) & & -0.1 & & \\
\hline Marginal effect of Income (k euros) on VoTT (euros $/ \mathrm{h}$ ) & & 1.1 & & \\
\hline Carpool VoTT (euros/hour) & & & 25.99 & 26.7 \\
\hline Marginal effect of Gender $(0=\mathrm{M} ; 1=\mathrm{F})$ on carpool VoTT (euros $/ \mathrm{h})$ & & & & 4.69 \\
\hline Marginal effect of Age (years) on carpool VoTT (euros/h) & & & & -0.09 \\
\hline Marginal effect of Income (k euros) on carpool VoTT (euros/h) & & & & 0.94 \\
\hline Train VoTT (euros/hour) & & & 16.7 & 16.6 \\
\hline Marginal effect of Gender $(0=\mathrm{M} ; 1=\mathrm{F})$ on train VoTT (euros $/ \mathrm{h})$ & & & & 3.75 \\
\hline Bus VoTT (euros/hour) & & & 20.73 & 20.68 \\
\hline Marginal effect of Gender $(0=\mathrm{M} ; 1=\mathrm{F})$ on bus VoTT $($ euros $/ \mathrm{h})$ & & & & 3.24 \\
\hline Marginal effect of Age (years) on bus VoTT (euros/h) & & & & -0.1 \\
\hline Value of other passenger (euros) & -4.56 & -5.14 & -4.37 & -4.39 \\
\hline Marginal effect of Travel time (hours) on cost of other pass. (euros) & & -1.88 & & \\
\hline
\end{tabular}

Table 8: Passengers' vales of travel time and of extra passenger

Carpool as a passenger VoTT is around 26 euros per hour and 60\% higher than train VoTT and 20\% higher than bus VoTT. This is constant across specifications and seems robust. The differences in VoTT can be explained by differences in transport experiences. Other things being equal, individuals making a trip as passenger are willing to pay more to decrease their carpool travel time than their train travel time.

Specification (4) in Tables 7 and 8 reveals a strong gender effect in the carpool as passenger VoTT. Females' carpool VoTT is 4.69 euros higher than males'. The same gender effect, although smaller, is present for the train and bus VoTT. We also find a positive effect of income $(+0.94$ euros $/ \mathrm{h}$ per $1000 \mathrm{k}$ euros) and a negative effect of age (-0.09 euros/h per year) on carpool as passenger VoTT. These socioeconomic drivers are specific to carpool. The amplitude of User Type variations in VoTT as passenger is lower than the amplitude of Mode type variations.

The value of an extra passenger is around -4.5 euros per passenger. The effect is $f$ same magnitude across specifications. The presence of another carpooled passenger (besides the driver) is clearly perceived as an inconvenience. We do not find any socio-economic drivers to this effect. 


\section{Discussion}

\subsection{Main results}

5.1.1. Values of travel time

Our first contribution concerns the VoTT for carpool long-distance trips. We find that, on average, carpool VoTT are higher than other competing modes VoTT. When driving, estimated carpool VoTT is $13 \%$ higher than solo driving VoTT (see Table 6). When making the trip as a passenger, estimated carpool VoTT is $26.7 € /$ hour, which is larger than bus $(20.68 € /$ hour $)$ and train $(16.6 € /$ hour $)$ VoTT. These findings show clear-cut Mode valued variation in VoTT, as suggested by Wardman (2004). For drivers, a potential explanation of this difference is the invasion of her personal space during the length of the trip, making it less comfortable (Correia \& Viegas, 2011). Moreover, there are implicit carpool conventions which could lower carpool decision probability. For instance, carpoolers are expected to have or at least start a conversation during the trip. This carpool specific feature could also explain differences in VoTT for passengers. This effect can even be stronger for passengers as implicit carpool conventions prevent the passenger from performing tasks he would like during her journey, such as read a newspaper, work or use her smartphone. Moreover, these activities could be more easily performed in train or bus than in car because of the more constant speed of these modes (see Ettema et al. (2012) for the effects on in-vehicle activities on travel satisfaction).

In line with literature on VoTT (Small, 2012), we also find User type variations in VoTT. Specifically, carpool VoTT are shown to be correlated with socio-economic variables. Thus, carpool both as a driver and a passenger VoTT decreases with age and increases with income. This common income effect (see Jara-Díaz \& Videla, 1989) is related to the opportunity cost of time: wealthier individuals seem to be willing to pay more to save travel time. Other passengers competing modes (bus and train) VoTT are not correlated with income. One potential explanation could be that the income-related differences in opportunity cost of time are lower in these modes because individuals can use their time as they wish (using smartphones, reading, listening to audio content...). In a study on Paris region, Bounie et al. (2019) find that optimal connectivity to mobile phone and internet in public transport would reduce 
public transport VoTT by $12 \%$. The higher constraints on carpool travel conditions (compared to other passenger modes) described above appear more prejudicial for wealthier individual.

5.1.2.Effect of the number of passengers in the car

Our second input to the literature is the effect of the number of extra passengers on the carpool utility (VoEP and VoOP). For drivers, this effect is clearly gender-specific. Other things being equal, female drivers prefer having two passengers over one passenger, whereas male drivers prefer having only one passenger over two passengers. This effect has not been documented previously in the literature. We can suppose that safety issues are playing here: female seem to feel more comfortable and secure with two passengers than with one passenger. During interviews with carpoolers, Créno \& Cahour (2014) identified carpooling with no other passenger as a fear for carpool women. Other things being equal, passenger carpool utility decreases with the number of other passengers in the car. This result is consistent with a previous study by Levin (1982).

\subsubsection{Other results}

We also find that other things being equal, pure preference (or aversion) for carpool is heterogeneously distributed across population. We show that this preference is correlated with socio-economic characteristics. We find a positive effect of income and a negative effect of age on choosing carpooling as a driver over solo. These effects are consistent with the existing literature (see for example Ferguson (1995) for the income effect and Gärling et al. (2000) for the age effect). However, this literature does not explicitly distinguish being a carpool driver from being a carpool passenger. Thus Ferguson (1995) attributes the association between carpooling and income to individual car ownership. The design of our survey allows to control for this income effect, and reinforces previous results in the literature.

\subsection{Policy implications}

\subsubsection{HOV Lane}

Our results are of interest to increase efficiency of High Occupancy Vehicle (HOV). Carpool as driver VoTT is $13 \%$ higher than solo driver VoTT. It implies that other ting being equal, an HOV lane could equal time cost of solo travel and time cost of carpool travel if the gain in travel time due to HOV is 
$11.5 \%$ of the total travel time. ${ }^{25}$ As pickup and drop-off frictions may cause time loss to carpool driver, it is reasonable to assume this $11.5 \%$ time gain to be lower threshold.

\subsubsection{Targeting rightly the right people}

As socio-economic characteristics appears to be crucial in carpooling choice, it seems that promotion campaign and matching platforms should take it into account. For example, as it appears that female drivers prefer to carry two passengers over one passenger, specific carpool supply and promotion could be elaborated to meet this preference.

\subsubsection{Setting the right price}

Our results allow to sharpen carpool pricing, which is of interest for local authority or web matching platforms such BlaBlaCar. For instance, the cost of an extra passenger from a driver perspective is around $10 €$, regardless the distance. It gives information on how much the driver should be paid to accept to carry one more passenger. In the same vein, our results provide details on how much passengers can be charged, with respect to the prices of competing modes. Our results suggest that the carpool prices and reward could be made of a fixed part associated with number of passengers and a variable part which increases with the length of the trip.

\subsubsection{Transport modeling}

Our estimated VoTT can be used as preliminary results to differentiate carpool as a driver and as a passenger from other transport modes. This would allow to improve long-distance transport models, and to produce better estimations of expected gains due to carpool promotion. These results can also be used as priors to construct efficient designs for a further stated preferences survey.

${ }^{25} 1-1 / 1.13=0.115$ 


\subsection{Limitations}

\subsubsection{High driver VoTT}

For drivers, computed VoTT are high compared to the literature. Small (2012) relates that commuting VoTT typically averages one half of the gross wage rate. ${ }^{26}$ Quinet (2013) gives an "official" VoTT for long distance trips in France of $15.7 €$ per hour. ${ }^{27}$ Several reasons might explain these gaps of at least 20 euros between our values and those from the literature. First, our experiment has a willingness-to-accept structure, because drivers are willing to accept an amount of money to put up with something negative for them, carpooling. This is rather unusual in the VoTT literature, where studies mostly used willingness-to-pay methods. Horowitz \& McConnell (2002) showed that willingness to accept is substantially higher than willingness to pay. In the specific field of VoTT valuation, De Borger \& Fosgerau (2008) show that the gap is a factor of four. Second, the difference might be due to the fact that individual in our driver sample are chosen among the individuals owning a car and then a high income on average. Third, another limit comes from the design of the stated survey experiment. We did not propose a null alternative (i.e. no trip) and respondents were "forced" to make the trip.

\subsubsection{No null alternative}

Following the previous limitation, there was no null alternative (or external choice) proposed in the survey: individuals had to pick one transport mode, they were not able to renounce the trip (to opt-out). Moreover, choice situations in the survey deliberately do not replicate real life situation because we wanted to design situations in which people trade-off between modes. For these reasons, we do not trust the mode shares obtained in the survey. However, we do not think that the absence of null alternative increases the hypothetical bias in this study because the estimated train VoTT is close to previous results (Abrantes \& Wardman, 2011, Quinet, 2013).

\subsubsection{External validity}

\footnotetext{
${ }^{26}$ According to INSEE (2018), the average gross wage rate in France in 2014 was $17.3 €$.

${ }^{27}$ The official value of travel time for long-distance trips in France given by Quinet (2013) is 14.4 €2010/hours, which transforms into $15.7 € 2018$ /hour by taking into account the inflation.
} 
The externality validity of our results is questionable. Our sample is representative of the French population only, but we do not see that as a limit as we take care to explicitly control for socio-economic characteristics of the individual in the econometric approach. However, there might be inter-countries differences depending on country-specific long-distance carpool habits. France is characterized by the emergence of successful carpool matching firm, BlaBlaCar. This firm has been founded in 2006 and has successfully developed in France and 22 other countries. The success of this carpool platform and the diffusion of its standards makes carpool a well-known and trustworthy transport mode in France. Our guess is that lower knowledge and habit to carpool would decrease the carpool choice probability and then increase carpool VoTT, VoEP and VoOP.

\subsection{Further research}

Future research could enhance our knowledge of long-distance carpool by:

Finding factors which make a solo driver become a carpool passenger. This is a promising way to decrease road traffic.

- Studying the effects of the carpooler profile on the carpool decision to increase matching platform efficiency. Question is with who does the driver feel comfortable enough to carpool?

\section{Conclusion}

This paper has used a discrete choice experiment survey to identify, measure and valuate the attributes of long-distance transport modes (bus, train, and car) for a trip as driver and as passenger, with a special focus on an emerging mode, carpooling. We estimate values of travel time for these modes of transport, and we reveal robust mode type variations in VoTT.

Our main conclusions can be summarized as follows: First, our study reveals a strong preference for driving solo over taking carpoolers in one's car. Second, we show that the VoTT for a driver who carpools is on average 13\% higher than the VoTT when driving alone in his/her car and that the VoTT for a carpool trip as passenger is on average $60 \%$ higher than train VoTT and 20\% higher than bus VoTT. Third, we find that individuals traveling as carpool passenger incur a "discomfort" cost of on average 4.5 euros per extra passenger in the same vehicle. Finally, we also identify strong socio- 
economic effects. The gender, the age and the income clearly drives the probability of carpooling. These variables play through three different channels: a pure effect on the probability of carpool choice, and mitigations of the carpool VoTT and of the cost of an extra passenger (this heterogeneity is captured with interaction terms). When they drive a car, females are less likely to carpool than male, but they prefer to carpool two passengers over only one passenger.

This paper contributes to the transport economics literature in several aspects. We add new values of travel time to a literature that has mostly focused on short distance trips made in car, whereas we focus on long-distance trips made by train, and more originally, by bus and carpool. In addition, our analysis includes original empirical evidences on an emerging long-distance trip mode, the carpool. We identify clear socio-economic drivers of preference or aversion for carpooling. Finally, we introduce and measure the effect of the number of other individuals in the car, that turns out to be an important attribute of a carpool trip. This attribute is related to the crowding effect identified in public transport.

Our results help to understand the relatively low mode shares of carpool for long-distance trips despite the recent trends. Carpool turns to be a relatively uncomfortable transport mode as other things being equal, one minute carpooling decreases more the utility of a trip than one minute in competing transport modes (car solo, bus or train). This suggests that the monetary price (for passengers) and gain (for drivers) of carpooling are the main tools available to increase carpool use. 


\section{References}

Abrantes, P. A., \& Wardman, M. R. (2011). Meta-analysis of UK values of travel time: An update. Transportation Research Part A: Policy and Practice, 45(1), 1-17.

ADEME (2015a). Enquête auprès des utilisateurs du covoiturage longue distance, contract 1466C0095, 109p.

ADEME (2015b). Leviers d'actions pour favoriser le covoiturage de courte distance, évaluation de l'impact sur les polluants atmosphériques et le $\mathrm{CO} 2$-Leviers d'actions, benchmark et exploitation de l'enquête nationale Transports et déplacements (ENTD), contract 1362C0009, 233p.

Barrat, G. (2017, September 25). Need a ride? Carpooling offers a short-cut in the drive to end congestion. The Guardian. Retrieved from https://www.theguardian.com/small-business-network /2017/sep/25/carpooling-mainstream-congestion-splt-gokid.

Becker, H., Ciari, F., \& Axhausen, K. W. (2017). Comparing car-sharing schemes in Switzerland: User groups and usage patterns. Transportation Research Part A: Policy and Practice, 97, 17-29.

BlaBlaCar \& LE BIPE (2019). Zero empty seats, report, 22p.

Bounie, N., Adoue, F., Koning, M., \& L'hostis, A. (2019). What value do travelers put on connectivity to mobile phone and Internet networks in public transport? Empirical evidence from the Paris region. Transportation Research Part A: Policy and Practice, 130, 158-177.

Buliung, R. N., Soltys, K., Bui, R., Habel, C., \& Lanyon, R. (2010). Catching a ride on the information super-highway: toward an understanding of internet-based carpool formation and use. Transportation, 37(6), 849-873.

CGDD, (2016). Covoiturage longue distance : état des lieux et potentiel de croissance. Etudes \& Documents du Commissariat Général au Développement Durable, no. 146, May

Charles, K. K., \& Kline, P. (2006). Relational costs and the production of social capital: evidence from carpooling. The Economic Journal, 116(511), 581-604. 
Correia, G., \& Viegas, J. M. (2011). Carpooling and carpool clubs: Clarifying concepts and assessing value enhancement possibilities through a Stated Preference web survey in Lisbon, Portugal. Transportation Research Part A: Policy and Practice, 45(2), 81-90.

Créno, L., \& Cahour, B. (2014, September). Chronicles of Lived Experiences for studying the process of trust building in carpooling. In Proceedings of the 2014 European Conference on Cognitive Ergonomics (p. 15). ACM.

Croissant, Y. (2012). Estimation of multinomial logit models in R: The mlogit Packages. $R$ package version $0.2-2$.

Dargay, J. M., \& Clark, S. (2012). The determinants of long distance travel in Great Britain. Transportation Research Part A: Policy and Practice, 46(3), 576-587.

De Borger, B., \& Fosgerau, M. (2008). The trade-off between money and travel time: A test of the theory of reference-dependent preferences. Journal of Urban Economics, 64(1), 101-115.

Delhomme, P., \& Gheorghiu, A. (2016). Comparing French carpoolers and non-carpoolers: which factors contribute the most to carpooling?. Transportation Research Part D: Transport and Environment, 42, 1-15.

DeSerpa, A. C. (1971). A theory of the economics of time. The Economic Journal, 81(324), 828-846.

De Luca, S., \& Di Pace, R. (2015). Modelling users' behaviour in inter-urban carsharing program: A stated preference approach. Transportation Research Part A: Policy and Practice, 71, 59-76.

Ettema, D., Friman, M., Gärling, T., Olsson, L. E., \& Fujii, S. (2012). How in-vehicle activities affect work commuters' satisfaction with public transport. Journal of Transport Geography, 24, 215-222.

Farajallah, M., Hammond, R. G., \& Pénard, T. (2019). What Drives Pricing Behavior in Peer-to-Peer Markets? Evidence from the Carsharing Platform BlaBlaCar. Information Economics and Policy.

Ferguson, E. (1995). Demographics of carpooling. Transportation Research Record, 142-150. 
Finger, M., Bert, N., \& Kupfer, D. (2017). Infrastructure Funding Challenges in the Sharing Economy, Transport Area of the Florence School of Regulation (FSR Transport) at the European University Institute (EUI). Report prepared for the Research for the TRAN Committee of the European Parliament, Directorate-General for Internal Policies.

Fosgerau, M. (2006). Investigating the distribution of the value of travel time savings. Transportation Research Part B: Methodological, 40(8), 688-707.

Gärling, T., Gärling, A., \& Johansson, A. (2000). Household choices of car-use reduction measures. Transportation Research Part A: Policy and Practice, 34(5), 309-320.

Haywood, L., Koning, M., \& Monchambert, G. (2017). Crowding in public transport: Who cares and why?. Transportation Research Part A: Policy and Practice, 100, 215-227.

Hensher, D. A., \& Greene, W. H. (2003). The mixed logit model: the state of practice. Transportation, 30(2), 133-176.

Hensher, D. A., \& Rose, J. M. (2007). Development of commuter and non-commuter mode choice models for the assessment of new public transport infrastructure projects: a case study. Transportation Research Part A: Policy and Practice, 41(5), 428-443.

Horowitz, J. K., \& McConnell, K. E. (2002). A review of WTA/WTP studies. Journal of Environmental Economics and Management, 44(3), 426-447.

INSEE (2018). Salaire horaire: l'importance de la catégorie socioprofessionnelle et du diplôme. INSEE Focus $n^{\circ} 116$.

Jara-Díaz, S. R., \& Videla, J. (1989). Detection of income effect in mode choice: theory and application. Transportation Research Part B: Methodological, 23(6), 393-400.

Lam, T. C., \& Small, K. A. (2001). The value of time and reliability: measurement from a value pricing experiment. Transportation Research Part E: Logistics and Transportation Review, 37(2-3), 231-251.

Levin, I. P. (1982). Measuring tradeoffs in carpool driving arrangement preferences. Transportation, $11(1), 71-85$. 
McFadden D. (1974). Conditional logit analysis of qualitative choice behaviour. In: Zarembka P., ed., Frontiers in Econometrics. New York, NY: Academic Press 1974, 105-42.

Monchambert, G., \& Proost, S. (2019). How Efficient are Intercity Railway Prices and Frequencies in Europe? Comparing a Corridor in Belgium and in France. Journal of Transport Economics and Policy, 53(4), 323-347.

Montero, J. J. (2019). Regulating Transport Platforms: The Case of Carpooling in Europe. In The Governance of Smart Transportation Systems (pp. 13-35). Springer, Cham.

Neoh, J. G., Chipulu, M., \& Marshall, A. (2017). What encourages people to carpool? An evaluation of factors with meta-analysis. Transportation, 44(2), 423-447.

Patterson, Z., Ewing, G., \& Haider, M. (2005). Gender-based analysis of work trip mode choice of commuters in suburban Montreal, Canada, with stated preference data. Transportation Research Record, 1924(1), 85-93.

Quinet, E. (2013). L'évaluation socio-économique des investissements publics, rapport du Commissariat Général à la Stratégie et à la Prospective. La Documentation Française, Paris.

Razemon, O. (2013). Comment Le Covoiturage Fait Baisser Le Prix Du Train. L'interconnexion n'est plus assurée. Retrieved from http://transports.blog.lemonde.fr/2013/04/28/comment-le-covoituragefait-baisser-le-prix-du-train/

Rosenbloom, S., \& Burns, E. (1993). Gender differences in commuter travel in Tucson: implications for travel demand management programs.

Scheiner, J. (2014). Gendered key events in the life course: effects on changes in travel mode choice over time. Journal of Transport Geography, 37, 47-60.

SDES (2018). La mobilité à longue distance des Français en 2016. Chiffres et statistiques. Paris, Commissariat Général au développement Durable: $4 \mathrm{p}$.

Shaheen, S., Stocker, A., \& Mundler, M. (2017). Online and app-based carpooling in France: Analyzing users and practices - A study of BlaBlaCar. Disrupting Mobility, 181-196. 
Small, K. A. (2012). Valuation of travel time. Economics of Transportation, 1(1-2), 2-14.

Su, F., \& Bell, M. G. (2009). Transport for older people: Characteristics and solutions. Research in transportation economics, 25(1), 46-55.

Teal, R. F. (1987). Carpooling: who, how and why. Transportation Research Part A: General, 21(3), 203-214.

Train, K. E. (2009). Discrete choice methods with simulation. Second Edition. Cambridge University Press.

Truong, T. P., \& Hensher, D. A. (1985). Measurement of travel time values and opportunity cost from a discrete-choice model. The Economic Journal, 438-451.

Tseng, Y. Y., \& Verhoef, E. T. (2008). Value of time by time of day: A stated-preference study. Transportation Research Part B: Methodological, 42(7-8), 607-618.

Wagner, N. (2016). Covoiturage longue distance : état des lieux et potentiel de croissance. Collection « Études et documents » du Service de l'Économie, de l'Évaluation et de l'Intégration du Développement Durable (SEEIDD) du Commissariat Général au Développement Durable (CGDD).

Wang, R. (2011). Shaping carpool policies under rapid motorization: the case of Chinese cities. Transport Policy, 18(4), 631-635.

Wardman, M. (2004). Public transport values of time. Transport policy, 11(4), 363-377.

White, G. (2018, November 12). French car-pool app Blablacar branching into bus lines. Reuters. Retrieved from https://www.reuters.com/article/us-france-blablacar/french-car-pool-app-blablacarbranching-into-bus-lines-idUSKCN1NH25P. 


\section{Appendices}

\begin{tabular}{|c|c|c|c|c|c|c|}
\hline Mode & Variable & Mean & $\mathrm{sd}$ & Min & Max & Step size \\
\hline \multirow[t]{4}{*}{ Train } & Travel time (min.) & 60,19 & 14,14 & 40 & 80 & 10 \\
\hline & Early arrival (min.) & 31,71 & 42,98 & 0 & 120 & 15 \\
\hline & Late arrival (min.) & 21,41 & 28,82 & 0 & 90 & 15 \\
\hline & Price $(€)$ & 12,45 & 5,63 & 5 & 20 & 5 \\
\hline \multirow[t]{4}{*}{ Bus } & Travel time & 74,92 & 10,12 & 60 & 90 & 5 \\
\hline & Early arrival & 25,24 & 37,08 & 0 & 120 & 15 \\
\hline & Late arrival & 14,86 & 21,69 & 0 & 75 & 15 \\
\hline & Price & 8,33 & 4,10 & 2 & 15 & 1 \\
\hline \multirow[t]{5}{*}{ Carpool A } & Travel time & 74,76 & 10,06 & 60 & 90 & 5 \\
\hline & Early arrival & 7,55 & 11,27 & 0 & 30 & 5 \\
\hline & Late arrival & 5,71 & 9,13 & 0 & 30 & 5 \\
\hline & Price & 7,48 & 1,71 & 5 & 10 & 1 \\
\hline & $\mathrm{Nb}$ of other ind. & 1,99 & 0,82 & 1 & 3 & 1 \\
\hline \multirow[t]{5}{*}{ Carpool B } & Travel time & 74,65 & 10,02 & 60 & 90 & 5 \\
\hline & Early arrival & 7,02 & 10,69 & 0 & 30 & 5 \\
\hline & Late arrival & 5,72 & 9,40 & 0 & 30 & 5 \\
\hline & Price & 7,49 & 1,72 & 5 & 10 & 1 \\
\hline & $\mathrm{Nb}$ of other ind. & 2,00 & 0,82 & 1 & 3 & 1 \\
\hline \multicolumn{2}{|c|}{ Mode choice: train } & $28 \%$ & & & & \\
\hline \multicolumn{2}{|c|}{ Mode choice: bus } & $21 \%$ & & & & \\
\hline \multicolumn{2}{|c|}{ Mode choice: carpool A } & $29 \%$ & & & & \\
\hline \multicolumn{2}{|c|}{ Mode choice: carpool B } & $22 \%$ & & & & \\
\hline \multicolumn{2}{|c|}{$\mathrm{Nb}$ of choice situations proposed } & 5908 & & & & \\
\hline
\end{tabular}

Table 9: Characteristics of the 100km passengers' tasks submitted to respondents

\begin{tabular}{llccccc}
\hline Mode & Variable & Mean & sd & Min & Max & Step size \\
\hline Train & Travel time (min.) & 164,40 & 51,32 & 90 & 240 & 30 \\
& Early arrival (min.) & 28,88 & 42,26 & 0 & 120 & 15 \\
& Late arrival (min.) & 32,48 & 44,06 & 0 & 120 & 15 \\
& Price (€) & 39,46 & 20,12 & 10 & 70 & 10 \\
\hline Bus & Travel time & 193,91 & 30,34 & 150 & 240 & 15 \\
& Early arrival & 23,82 & 36,34 & 0 & 120 & 15 \\
& Late arrival & 18,75 & 30,82 & 0 & 120 & 15 \\
& Price & 17,22 & 8,48 & 5 & 30 & 5 \\
\hline Carpool A & Travel time & 199,33 & 34,02 & 150 & 250 & 20 \\
& Early arrival & 6,37 & 9,88 & 0 & 30 & 5 \\
& Late arrival & 5,13 & 8,85 & 0 & 30 & 5 \\
& Price & 20,00 & 7,10 & 10 & 30 & 5 \\
& Nb of other ind. & 1,98 & 0,82 & 1 & 3 & 1 \\
\hline Carpool B & Travel time & 199,35 & 34,25 & 150 & 250 & 20 \\
& Early arrival & 6,31 & 10,09 & 0 & 30 & 5 \\
& Late arrival & 5,54 & 9,38 & 0 & 30 & 5 \\
& Price & 19,98 & 7,04 & 10 & 30 & 5 \\
& Nb of other ind. & 1,98 & 0,82 & 1 & 3 & 1 \\
\hline Mode choice: train & $28 \%$ & & & & \\
Mode choice: bus & $28 \%$ & & & & \\
Mode choice: carpool A & $24 \%$ & & & & \\
Mode choice: carpool B & $20 \%$ & & & & \\
\hline Nb of choice situations proposed & 5908 & & & & \\
\hline
\end{tabular}

Table 10: Characteristics of the $300 \mathrm{~km}$ passengers' tasks submitted to respondents 


\begin{tabular}{|c|c|c|c|c|c|c|}
\hline Mode & Variable & Mean & sd & Min & Max & Step size \\
\hline \multirow[t]{4}{*}{ Train } & Travel time (min.) & 193,19 & 51,05 & 120 & 270 & 30 \\
\hline & Early arrival (min.) & 24,46 & 37,81 & 0 & 120 & 15 \\
\hline & Late arrival (min.) & 34,56 & 45,18 & 0 & 120 & 15 \\
\hline & Price $(€)$ & 77,70 & 42,51 & 10 & 150 & 10 \\
\hline \multirow[t]{4}{*}{ Bus } & Travel time & 343,51 & 50,78 & 270 & 420 & 30 \\
\hline & Early arrival & 26,91 & 40,61 & 0 & 120 & 15 \\
\hline & Late arrival & 27,79 & 39,34 & 0 & 120 & 15 \\
\hline & Price & 22,14 & 11,44 & 5 & 40 & 5 \\
\hline \multirow[t]{5}{*}{ Carpool A } & Travel time & 342,85 & 51,05 & 270 & 420 & 30 \\
\hline & Early arrival & 11,75 & 18,88 & 0 & 60 & 10 \\
\hline & Late arrival & 13,04 & 20,01 & 0 & 60 & 10 \\
\hline & Price & 32,22 & 8,45 & 20 & 45 & 5 \\
\hline & $\mathrm{Nb}$ of other ind. & 1,99 & 0,82 & 1 & 3 & 1 \\
\hline \multirow[t]{5}{*}{ Carpool B } & Travel time & 343,33 & 50,72 & 270 & 420 & 30 \\
\hline & Early arrival & 10,46 & 17,26 & 0 & 60 & 10 \\
\hline & Late arrival & 12,45 & 19,07 & 0 & 60 & 10 \\
\hline & Price & 32,19 & 8,52 & 20 & 45 & 5 \\
\hline & $\mathrm{Nb}$ of other ind. & 1,99 & 0,82 & 1 & 3 & 1 \\
\hline \multicolumn{2}{|c|}{ Mode choice: train } & $38 \%$ & & & & \\
\hline \multicolumn{2}{|c|}{ Mode choice: bus } & $27 \%$ & & & & \\
\hline \multicolumn{2}{|c|}{ Mode choice: carpool A } & $19 \%$ & & & & \\
\hline \multicolumn{2}{|c|}{ Mode choice: carpool B } & $16 \%$ & & & & \\
\hline \multicolumn{2}{|c|}{$\mathrm{Nb}$ of choice situations proposed } & 5900 & & & & \\
\hline
\end{tabular}

Table 11: Characteristics of the 500km passengers' tasks submitted to respondents

\begin{tabular}{llccccc}
\hline Mode & Variable & Mean & sd & Min & Max & Step size \\
\hline Train & Travel time (min.) & 253,98 & 50,75 & 180 & 330 & 30 \\
& Early arrival (min.) & 41,01 & 58,92 & 0 & 180 & 15 \\
& Late arrival (min.) & 46,06 & 62,41 & 0 & 180 & 15 \\
& Price $(€)$ & 102,14 & 46,71 & 30 & 180 & 10 \\
\hline Bus & Travel time & 474,81 & 50,88 & 400 & 550 & 30 \\
& Early arrival & 41,74 & 57,37 & 0 & 180 & 15 \\
& Late arrival & 36,41 & 53,83 & 0 & 180 & 15 \\
& Price & 29,98 & 12,85 & 10 & 50 & 5 \\
\hline Carpool A & Travel time & 474,59 & 51,25 & 400 & 550 & 30 \\
& Early arrival & 13,81 & 21,37 & 0 & 60 & 10 \\
& Late arrival & 13,23 & 20,64 & 0 & 60 & 10 \\
& Price & 44,95 & 10,06 & 30 & 60 & 5 \\
& Nb of other ind. & 2,00 & 0,81 & 1 & 3 & 1 \\
\hline Carpool B & Travel time & 473,00 & 50,52 & 400 & 550 & 30 \\
& Early arrival & 12,91 & 19,32 & 0 & 60 & 10 \\
& Late arrival & 11,38 & 17,78 & 0 & 60 & 10 \\
& Price & 44,91 & 10,03 & 30 & 60 & 5 \\
& Nb of other ind. & 1,98 & 0,82 & 1 & 3 & 1 \\
\hline Mode choice: train & $43 \%$ & & & & \\
Mode choice: bus & $27 \%$ & & & & \\
Mode choice: carpool A & $17 \%$ & & & & \\
Mode choice: carpool B & $13 \%$ & & & & \\
\hline Nb of choice situations proposed & 5900 & & & & \\
\hline
\end{tabular}

Table 12: Characteristics of the 700km passengers' tasks submitted to respondents 


\begin{tabular}{|c|c|c|c|c|}
\hline & (1) & (2) & (3) & (4) \\
\hline \multirow[t]{2}{*}{ Intercept - mean } & $-1.160^{* * *}$ & 0.216 & $-0.969^{* * *}$ & $1.354^{* * *}$ \\
\hline & $(0.132)$ & $(0.324)$ & $(0.139)$ & $(0.479)$ \\
\hline \multirow[t]{2}{*}{ Intercept - sd } & $3.776^{* * *}$ & $3.640^{* * * *}$ & $3.807^{* * * *}$ & $3.714^{* * *}$ \\
\hline & $(0.189)$ & $(0.183)$ & $(0.190)$ & $(0.187)$ \\
\hline \multirow[t]{2}{*}{ Gain from carpooling (euros) } & $0.016^{* * *}$ & $0.019^{* * *}$ & $0.021^{* * *}$ & $0.021^{* * * *}$ \\
\hline & $(0.002)$ & $(0.002)$ & $(0.002)$ & $(0.002)$ \\
\hline \multicolumn{5}{|l|}{ Travel time effects } \\
\hline \multirow[t]{2}{*}{ Travel time (hours) } & $-0.859^{* * *}$ & $-1.253^{* * *}$ & & \\
\hline & $(0.053)$ & $(0.180)$ & & \\
\hline \multirow[t]{2}{*}{ Trav. Time x Age } & & $0.016^{* * *}$ & & \\
\hline & & $(0.003)$ & & \\
\hline \multirow[t]{2}{*}{ Trav. Time x Gender } & & 0.022 & & \\
\hline & & $(0.105)$ & & \\
\hline \multirow{2}{*}{ Trav. Time $\mathrm{x}$ Income } & & $-0.137^{* * * *}$ & & \\
\hline & & $(0.047)$ & & \\
\hline \multicolumn{5}{|l|}{ Travel time solo effects } \\
\hline \multirow[t]{2}{*}{ Travel Time solo (hours) } & & & $-0.815^{* * * *}$ & $-1.069^{* * *}$ \\
\hline & & & $(0.054)$ & $(0.184)$ \\
\hline \multirow[t]{2}{*}{ TT solo x Age } & & & & $0.012^{* * * *}$ \\
\hline & & & & $(0.004)$ \\
\hline \multirow[t]{2}{*}{ TT solo x Gender } & & & & 0.007 \\
\hline & & & & $(0.108)$ \\
\hline \multirow[t]{2}{*}{ TT solo $\mathrm{x}$ Income } & & & & $-0.140^{* * * *}$ \\
\hline & & & & $(0.049)$ \\
\hline \multicolumn{5}{|l|}{ Travel time carpool effects } \\
\hline \multirow[t]{2}{*}{ Travel Time carpool (hours) } & & & $-0.923^{* * *}$ & $-1.445^{* * *}$ \\
\hline & & & $(0.056)$ & $(0.190)$ \\
\hline \multirow[t]{2}{*}{ TT carpool x Age } & & & & $0.018^{* * *}$ \\
\hline & & & & $(0.004)$ \\
\hline \multirow[t]{2}{*}{ TT carpool x Gender } & & & & 0.049 \\
\hline & & & & $(0.107)$ \\
\hline TT carpool x Income & & & & $-0.139^{* * * *}$ \\
\hline & & & & $(0.047)$ \\
\hline Number of extra passengers effects & & & & \\
\hline $\mathrm{Nb}$ of extra pass. & $-0.198^{* * *}$ & $0.425^{*}$ & $-0.190^{* * *}$ & 0.216 \\
\hline & $(0.065)$ & $(0.251)$ & $(0.065)$ & $(0.267)$ \\
\hline $\mathrm{Nb}$ of extra pass. $\mathrm{x}$ TT & & $-0.072^{* * *}$ & & -0.034 \\
\hline & & $(0.018)$ & & $(0.024)$ \\
\hline $\mathrm{Nb}$ of extra pass. $\mathrm{x}$ Age & & -0.006 & & -0.005 \\
\hline & & $(0.005)$ & & $(0.005)$ \\
\hline $\mathrm{Nb}$ of extra pass. $\mathrm{x}$ Gender & & $0.468^{* * *}$ & & $0.470^{* * * *}$ \\
\hline & & $(0.140)$ & & $(0.141)$ \\
\hline $\mathrm{Nb}$ of extra pass. $\mathrm{x}$ Income & & -0.095 & & -0.090 \\
\hline & & $(0.064)$ & & $(0.064)$ \\
\hline Individual effects & & & & \\
\hline Age (years) & & $-0.023^{* * *}$ & & $-0.044^{* * *}$ \\
\hline & & $(0.006)$ & & $(0.009)$ \\
\hline Gender $(0=\mathrm{M} ; 1=\mathrm{F})$ & & $-1.262^{* * * *}$ & & $-1.644^{* * * *}$ \\
\hline & & $(0.184)$ & & $(0.274)$ \\
\hline Income (k euros) & & $0.354^{* * * *}$ & & $0.548^{* * * *}$ \\
\hline & & $(0.085)$ & & $(0.119)$ \\
\hline Access time to closest rail station (min.) & & $-0.028^{* * * *}$ & & $-0.030^{* * * *}$ \\
\hline & & $(0.004)$ & & $(0.004)$ \\
\hline AIC & 2957.585 & 2916.555 & 2941.750 & 2902.061 \\
\hline Log Likelihood & -1473.792 & -1442.277 & -1464.875 & -1431.031 \\
\hline McFadden R2 & 0.409 & 0.422 & 0.423 & 0.426 \\
\hline Num. obs. & 3600 & 3600 & 3600 & 3600 \\
\hline Panel size & 225 & 225 & 225 & 225 \\
\hline
\end{tabular}

Notes. This table reports binomial mixed logit estimations of Eq. (1) and (2) where the intercept $\beta_{0} \sim \mathcal{N}(\mu, \sigma), \beta_{1 ; s}=\beta_{1 ; c p d}$ (columns (1) and (2)), $\gamma_{i}=0$ (columns (1) and (3)) and $\delta_{i}=\theta_{i}=0$ (columns (1), (2), and (3)). The dependent variable is the mode choice between "solo" and "carpool". The reference alternative is "solo". Standard errors in parentheses. ***p $<$ $0.01, * * p<0.05, * p<0.1$.

Table 13: Empirical results from the drivers' model 


\begin{tabular}{lcc}
\hline & $(\mathbf{1})$ & $\mathbf{( 2 )}$ \\
\hline Price (euros) & $-0.027^{* * *}$ & $-0.027^{* * *}$ \\
Travel time effects & $(0.001)$ & $(0.001)$ \\
Travel time (hours) & $-0.695^{* * *}$ & $-0.668^{* * *}$ \\
TT x Age & $(0.012)$ & $(0.038)$ \\
TT x Gender & & $0.003^{* * *}$ \\
& & $(0.001)$ \\
TT x Income & & $-0.121^{* * * *}$ \\
& & $(0.021)$ \\
Travel time train effects & & $-0.030^{* * * *}$ \\
\end{tabular}

Travel time train

$$
\begin{array}{cc}
-0.473^{\text {*** }} & -0.535^{* * *} \\
(0.022) & (0.082) \\
& 0.003^{*} \\
& (0.002) \\
& -0.107^{* *} \\
& (0.046) \\
& -0.009
\end{array}
$$

TT train $x$ Age

TT train x Gender

TT train $\mathrm{x}$ Income

\section{Travel time carpool effects}

Travel time carpool

$$
\begin{array}{cc}
-0.736^{* * *} & -0.728^{* * *} \\
(0.013) & (0.044) \\
& 0.003^{* * *} \\
& (0.001) \\
& -0.134^{* * *} \\
& (0.025) \\
& -0.027^{* *} \\
& (0.011)
\end{array}
$$

\section{Travel time bus effects}

Travel time bus

$$
\begin{array}{cc}
-0.587^{* * *} & -0.629^{* * *} \\
(0.013) & (0.044) \\
& 0.003^{* * * *} \\
& (0.001) \\
& -0.093^{* * *} \\
& (0.025) \\
& -0.018 \\
& (0.012)
\end{array}
$$

\section{Number of carpool passengers effects}

$\mathrm{Nb}$ of other pass.

$$
\begin{gathered}
-0.122^{* * *} \\
(0.013)
\end{gathered}
$$

$$
0.015
$$$$
-0.124^{* * *}
$$$$
-0.183^{* * *}
$$$$
(0.052)
$$$$
\text { (0.013) }
$$

$-0.051^{* * *}$

$-0.003$

$(0.005)$

$(0.005)$

0.001

0.001

$(0.001)$

$(0.001)$

0.019

0.023

(0.026)

(0.026)

0.005

0.005

(0.012)

(0.012)

Individual effects - carpool

Intercept carpool - mean

$\begin{array}{cccc}-0.406^{* * *} & -0.173 & 0.275^{* * *} & 0.323^{*} \\ (0.036) & (0.118) & (0.049) & (0.181)\end{array}$


Intercept carpool - sd

Age - carpool (years)

Gender $-\operatorname{carpool}(0=\mathrm{M} ; 1=\mathrm{F})$

Income - carpool (k euros)

Access time to clos. rail st. - carpool (min)

High speed station - $\operatorname{carpool}(0=\mathrm{N} ; 1=\mathrm{Y})$

Individual effects - bus

Intercept bus - mean

Intercept bus - sd

Age - bus (years)

Gender - bus $(0=\mathrm{M} ; 1=\mathrm{F})$

Income - bus (k euros)

Access time to clos. rail st. - bus (min.)

High speed station - bus $(0=\mathrm{N} ; 1=\mathrm{Y})$

\begin{tabular}{|c|c|c|c|}
\hline \multirow{12}{*}{$\begin{array}{l}2.736^{* * *} \\
(0.043)\end{array}$} & $2.764^{* * *}$ & \multirow{12}{*}{$\begin{array}{l}2.824^{* * *} \\
(0.044)\end{array}$} & $2.837^{* * * *}$ \\
\hline & $(0.044)$ & & $(0.044)$ \\
\hline & $-0.011^{* * *}$ & & $-0.010^{* * *}$ \\
\hline & $(0.002)$ & & $(0.003)$ \\
\hline & $0.524^{* * * *}$ & & $0.633^{* * * *}$ \\
\hline & $(0.062)$ & & $(0.099)$ \\
\hline & $0.060^{* *}$ & & $0.119^{* * *}$ \\
\hline & $(0.028)$ & & $(0.045)$ \\
\hline & $-0.000^{* *}$ & & $-0.000^{* *}$ \\
\hline & $(0.000)$ & & $(0.000)$ \\
\hline & $-0.235^{* * *}$ & & $-0.212^{* * *}$ \\
\hline & $(0.046)$ & & $(0.047)$ \\
\hline$-0.318^{* * *}$ & $-0.515^{* * *}$ & $-0.245^{* * *}$ & $-0.364^{*}$ \\
\hline$(0.033)$ & $(0.115)$ & $(0.051)$ & (0.189) \\
\hline $2.221^{* * * *}$ & $2.166^{* * *}$ & $2.211^{* * * *}$ & $2.171^{* * * *}$ \\
\hline \multirow[t]{11}{*}{$(0.037)$} & $(0.036)$ & $(0.037)$ & $(0.036)$ \\
\hline & $0.010^{* * *}$ & & $0.010^{* * *}$ \\
\hline & $(0.002)$ & & $(0.003)$ \\
\hline & $-0.104^{*}$ & & $-0.179^{*}$ \\
\hline & $(0.060)$ & & $(0.103)$ \\
\hline & $-0.083^{* * *}$ & & -0.065 \\
\hline & $(0.028)$ & & $(0.048)$ \\
\hline & $-0.005^{* * *}$ & & $-0.005^{* * *}$ \\
\hline & $(0.001)$ & & $(0.001)$ \\
\hline & -0.001 & & -0.013 \\
\hline & $(0.048)$ & & $(0.048)$ \\
\hline $0.101^{* * *}$ & $0.088^{* * *}$ & $0.058^{* * *}$ & $0.058^{* * *}$ \\
\hline$(0.019)$ & $(0.019)$ & $(0.019)$ & $(0.019)$ \\
\hline$-0.360^{* * *}$ & $-0.372^{* * *}$ & $-0.414^{* * *}$ & $-0.417^{* * *}$ \\
\hline$(0.020)$ & $(0.021)$ & $(0.021)$ & $(0.021)$ \\
\hline 49328.623 & 49126.464 & 48873.065 & 48805.539 \\
\hline 24655.311 & -24537.232 & -24425.532 & -24368.769 \\
\hline 0.231 & 0.235 & 0.238 & 0.240 \\
\hline 23616 & 23616 & 23616 & 23616 \\
\hline 1476 & 1476 & 1476 & 1476 \\
\hline
\end{tabular}

Schedule delay effects

Early schedule delay (hours)

Late schedule delay (hours)

AIC

Log Likelihood

McFadden R2

Num. obs.

Sample size

Notes. This table reports mixed multinomial logit estimations of Eq. (3) and (4) when the intercepts $\beta_{0} \sim \mathcal{N}(\mu, \sigma), \beta_{1 ; c p p}=\beta_{1 ; b}=\beta_{1 ; t}$ (columns (1) and (3)), and $\gamma_{i}=\delta_{i}=\theta_{i}=0$ (columns (1) and (3)). The dependent variable is the mode choice between "bus", "train", "carpool A", and "carpool B". The reference alternative is "train". Standard errors in parentheses. $* * * p<0.01, * * p<0.05, * p<0.1$.

Table 14: Empirical results from the passengers' model 